\title{
ANESTESIA EM RUMINANTES
}

\author{
ANESTHESIA IN RUMINANTS
}

\author{
Jardel de Azevedo Silva ${ }^{1 \oplus}$, Erica Emerenciano de Albuquerque ${ }^{1}$, Ana Lucélia de Araújo ${ }^{2}$, $^{\circ}$ \\ Pedro Isidro da Nóbrega Neto ${ }^{3 \odot}$
}

\section{RESUMO}

Pós-graduando (a) do Programa de Pós-Graduação em Ciência e Saúde Animal (PPGCSA), curso de Medicina Veterinária, Universidade Federal de Campina Grande (UFCG), Patos, Paraíba, Brasil.

Professora do curso de Medicina Veterinária, Instituto Federal de Educação da Paraíba (IFPB), Sousa, Paraíba, Brasil.

Professor do curso de Medicina Veterinária, Universidade Federal de Campina Grande (UFCG), Patos, Paraíba, Brasil.

Autor para correspondência: pedroisidro@ymail.com

Revista Brasileira de Buiatria Clínica Cirúrgica,

Volume 3, Número 2, 2021

ISSN 2763-955X

DOI:10.4322/2763-955X.2021.018

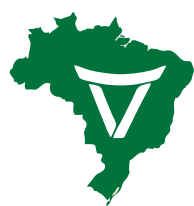

Associação Brasileira de Buiatria
A anestesiologia direcionada aos ruminantes se desenvolve concomitantemente à evolução dos fármacos e pesquisas na área de bem-estar animal que impulsionam o emprego de métodos que garantam prevenção/bloqueio da dor. Não só as técnicas anestésicas têm evoluído, mas também os cuidados pré-anestésicos também se adequaram para garantir cada vez mais segurança ao paciente ruminante durante todo o ato anestésico. A sedação nesses animais pode ser requerida para realizar procedimentos cirúrgicos, diagnósticos e/ou clínicos. Para tanto, os grupos farmacológicos mais empregados são os fenotiazínicos, como a acepromazina, os benzodiazepínicos, como o midazolam e o diazepam, e os agonistas alfa-2 adrenérgicos, como a xilazina, a detomidina e a dexmedetomidina. $\mathrm{O}$ emprego de anestésicos locais permite a realização de intervenções cruentas com o paciente consciente e em estação, o que evita complicações decorrentes do decúbito, que pode provocar alterações hemodinâmicas, respiratórias e digestivas. $\mathrm{O}$ anestésico local mais comumente empregado é a lidocaína, no entanto quando há necessidade de maior tempo hábil, recomenda-se a ropivacaína, a bupivacaína ou a levobupivacaína. As técnicas de bloqueio locorregional e segmentar garantem insensibilização de cabeça, tronco e membros, de modo seguro e com baixo custo. A anestesia geral intravenosa ou inalatória visam garantir estado de inconsciência e/ou imobilidade necessárias em procedimentos mais prolongados e/ou complexos. A anestesia intravenosa é caracterizada pela indução e manutenção anestésicas com fármacos administrados exclusivamente pela via intravenosa. Os agentes mais utilizados para esse fim são os derivados da fenciclidina (cetamina, escetamina e tiletamina); os miorrelaxantes (agonistas alfa-2 adrenérgicos, benzodiazepínicos e éter gliceril guaiacol) e os hipnóticos (propofol, tiopental e alfaxalona). O propofol é um agente indicado tanto para indução quanto para a manutenção da anestesia geral, pois permite indução suave e despertar rápido e tranquilo, sem efeitos cumulativos. O tiopental, um barbitúrico de curta duração, pode ser utilizado para indução anestésica, mas apresenta efeito cumulativo para fins de manutenção. A alfaxolona é um agente esteroide, ainda indisponível no Brasil, que garante períodos curtos de anestesia, permitindo intubação orotraqueal com menores impactos hemodinâmicos que o propofol e o tiopental. A anestesia inalatória é pouco empregada em procedimentos realizados no campo, pois demanda um aparelho de anestesia para que seja possível fornecer a mistura de gases ao paciente. Os principais anestésicos inalatórios utilizados em ruminantes são o isoflurano e o sevoflurano, ambos com impactos cardiovasculares semelhantes nesses animais. $\mathrm{O}$ desflurano promove menos impactos hemodinâmicos quando comparado aos demais agentes, mas é menos utilizado por apresentar alto custo, menor potência anestésica e requerer um vaporizador específico.

Palavras-chave: bloqueio anestésico, bovino, caprino, ovino, sedação.

\section{ABSTRACT}

Anesthesiology with emphasis on ruminants developed concurrently with the evolution of drugs and research in the area of animal welfare that promote the use of methods that ensure pain prevention/blockage. Not only the anesthetic techniques developed, but also the pre-anesthetic care were also adapted to ensure more and more safety to the ruminant patient throughout the anesthetic procedure. Sedation in these animals may be required to perform surgical, diagnostic and/or clinical procedures. Therefore, the most used pharmacological groups are phenothiazines, such as acepromazine; benzodiazepines, such as midazolam and diazepam; and alpha2adrenergic agonists, such as xylazine, detomidine and dexmedetomidine. The use of local anesthetics in ruminants allows the carrying out of bloody interventions with the patient conscious and in station, which avoids complications resulting from the decubitus, which can cause hemodynamic, respiratory and digestive alterations. The most commonly used local anesthetic is lidocaine, however, when more anesthetic time is needed, ropivacaine, bupivacaine or levobupivacaine are recommended. The locoregional and segmental blockade techniques ensure safe and low cost stunning of the head, trunk and limbs. In turn, intravenous or inhalational general anesthesia aim to ensure the state of unconsciousness and immobility necessary for longer and/or complex procedures. Intravenous anesthesia is characterized by anesthetic induction and maintenance with drugs administered exclusively intravenously. The most used agents for this purpose are phencyclidine derivatives (ketamine, sketamine and tiletamine); myorelaxants (alpha2-adrenergic agonists, benzodiazepines and glyceryl ether guaiacol) and hypnotics (propofol, thiopental and alphaxalone). Propofol is an agent indicated for both induction and maintenance of general anesthesia in ruminants, as it allows gentle induction and quick and quiet awakening, without cumulative effects. Thiopental, a short-acting barbiturate, can be used for anesthetic induction, but it has a cumulative effect for maintenance purposes. Alphaxolone is a steroid agent, not yet available in Brazil, which guarantees short periods of anesthesia, allowing orotracheal intubation with less hemodynamic impacts than propofol and thiopental. Inhalation anesthesia is still little used in procedures performed in the field, as it requires an anesthesia machine to be able to supply the mixture of gases to the patient. The main inhalational anesthetics used in ruminants are isoflurane and sevoflurane, both with similar cardiovascular impacts in these animals. Desflurane promotes less hemodynamic impacts when compared to other agents, but it is less used because of its high cost and lower anesthetic potency and requires a specific vaporizer. 


\section{INTRODUÇÃO}

A área de anestesiologia de ruminantes domésticos tem se desenvolvido substancialmente nas últimas décadas, em decorrência do desenvolvimento de novos fármacos, do melhor entendimento da farmacodinâmica e farmacocinética e da maior quantidade de pesquisas na área de bem-estar animal, que tem impulsionado o emprego de métodos seguros de prevenção/bloqueio da dor. Cabe salientar que os ruminantes experimentam a dor da mesma forma e intensidade que os demais mamíferos, apesar da "crença" antiga de que estes animais eram mais "resistentes" aos estímulos dolorosos. Na verdade, hoje sabe-se que eles, quando expostos à dor, apenas apresentam menos alterações comportamentais do que outras espécies, como caninos, felinos e equinos ${ }^{1}$.

A maioria dos procedimentos cirúrgicos aos quais os ruminantes são submetidos são realizados sob anestesia local, com o paciente apenas contido mecanicamente e/ou, como é mais recomendado, quimicamente, uma vez que a sedação pode reduzir a resposta de estresse e melhorar o conforto ${ }^{2,3}$. No entanto, quando a imobilidade total é necessária, por requerimento da técnica cirúrgica ou para a realização de procedimentos diagnósticos como tomografia computadorizada ou ressonância magnética, nas quais o animal precisa ser imobilizado por longos períodos de tempo, outras técnicas anestésicas precisam ser empregadas, tais como a total intravenosa ou a inalatória ${ }^{4}$.

Independentemente da técnica anestésica a ser empregada, algumas medidas precisam ser tomadas previamente, para reduzir os riscos de complicações decorrentes da contenção/anestesia, tais como:

- Adequado período de jejum e o correto posicionamento, visando prevenir o timpanismo e a regurgitação.

- Acomodação do paciente sobre um substrato macio e a manutenção da pressão arterial em níveis normais, como prevenção à mio/neuropatia pósanestésica.

- Intubação, posicionamento correto da cabeça e do pescoço e fornecimento de oxigênio, especialmente em cirurgias muito demoradas, para evitar/reduzir a depressão respiratória comumente observada em ruminantes em decúbito 5 .

Nesta revisão, serão abordados os temas sedação, anestesia local e anestesia injetável e inalatória em caprinos, ovinos e bovinos, incluindo os cuidados perianestésicos necessários, visando aumentar a segurança e a eficiência dos procedimentos anestésicos nestas espécies.

\section{SEDAÇÃO}

Apesar de os ruminantes normalmente aceitarem bem a contenção física, a administração de tranquilizantes/sedativos nestas espécies é requerida em muitas ocasiões, para realização de procedimentos cirúrgicos, diagnósticos e/ou de manejo clínico. Muitos fármacos estão disponíveis, como os fenotiazínicos, os benzodiazepínicos e os agonistas alfa-2 adrenérgicos, sendo que a escolha do fármaco ou associação a ser empregada normalmente decorre na análise do porte, temperamento e estado clínico do paciente, bem como do procedimento a ser realizado ${ }^{6}$.

\section{- Acepromazina}

A acepromazina é o tranquilizante fenotiazínico mais empregado na medicina veterinária. Praticamente não interfere na função respiratória, mas não produz analgesia e causa vasodilatação, que pode gerar hipotensão, principalmente em animais com hipovolemia e quando empregada em doses elevadas ${ }^{3}$. Causa relaxamento do músculo retrator do pênis, o que facilita a exposição peniana por tração, porém, em animais 
mais sensíveis, pode provocar prolapso peniano, que aumenta o risco de lesão ao órgão em animais em decúbito ${ }^{6}$.

Não altera a motilidade ruminal ${ }^{4}$, porém, devido ao seu efeito antiespasmódico da musculatura lisa, pode aumentar o risco de regurgitação transanestésica, especialmente se o paciente estiver em decúbito lateral ou dorsal ${ }^{7}$. No entanto, este mesmo efeito torna o fármaco indicado nos casos de urolitíase, quando o relaxamento da musculatura lisa pode facilitar a desobstrução uretral ${ }^{8}$. A acepromazina é particularmente útil na tranquilização de animais gestantes, pois altera muito pouco o fluxo sanguíneo uterino, não interferindo na oxigenação fetal ${ }^{9}$.

As doses usuais de acepromazina em ruminantes variam de 0,03 a 0,1 mg/kg, pelas vias subcutânea (SC), intramuscular (IM) ou intravenosa (IV). Quando administrada pela via IV, o efeito máximo é obtido em cerca de 15 minutos e a tranquilização pode persistir por até 6 horas $^{3}$.

Na rotina clínica dos autores, a acepromazina é mais utilizada quando se deseja acalmar o animal, porém evitando o decúbito, que normalmente ocorre quando se empregam fármacos mais potentes, como a xilazina.

\section{- Diazepam e Midazolam}

Embora pouco utilizados na rotina clínica de ruminantes, os benzodiazepínicos diazepam e midazolam podem ser úteis também nestas espécies. Provocam sonolência e pronunciado relaxamento muscular, sendo por isso utilizados como anticonvulsivantes. São fármacos muito seguros, pois alteram muito pouco os parâmetros cardiorrespiratórios, porém não causam analgesia e podem provocar ataxia, aumentando o risco de decúbito ${ }^{3}$. Quando usados isoladamente, podem provocar excitação paradoxal previamente à sedação em alguns animais, sendo por isso mais empregados em associação com outros sedativos ${ }^{10}$.
O midazolam é hidrossolúvel, podendo ser administrado pelas vias SC, IM ou IV.Já o diazepam é insolúvel em água, sendo comercializado diluído em propilenoglicol, que causa dor e dificulta a absorção do fármaco quando administrado pelas vias $\mathrm{SC}$ e IM, o que indica seu emprego pela via $I^{11}$.

Em ruminantes, as doses recomendadas do diazepam variam de 0,2 a $0,5 \mathrm{mg} / \mathrm{kg}$ e as do midazolam de 0,1 a $0,6 \mathrm{mg} / \mathrm{kg}$. Após a administração IV a latência é de cerca de 3 a 5 minutos e os efeitos mais pronunciados duram entre 20 e 30 minutos ${ }^{6,10,11}$. Uma vantagem adicional do uso dos benzodiazepínicos é que seus efeitos podem ser prontamente revertidos, com a administração do flumazenil, na dose de 0,01 a 0,02 mg/kg, via $\mathrm{IV}^{3}$.

\section{- Xilazina}

A xilazina é o fármaco mais utilizado na contenção química de ruminantes, em decorrência dos seus efeitos miorrelaxante, sedativo e analgésico visceral, mediados pelos receptores alfa-2 adrenérgicos centrais, do seu fácil acesso, do custo relativamente reduzi$\mathrm{do}^{2}$ e da extrema sensibilidade apresentada pelos ruminantes aos seus efeitos ${ }^{5}$. De modo interessante, existe uma variação desta sensibilidade aos efeitos da xilazina entre as espécies de ruminantes:

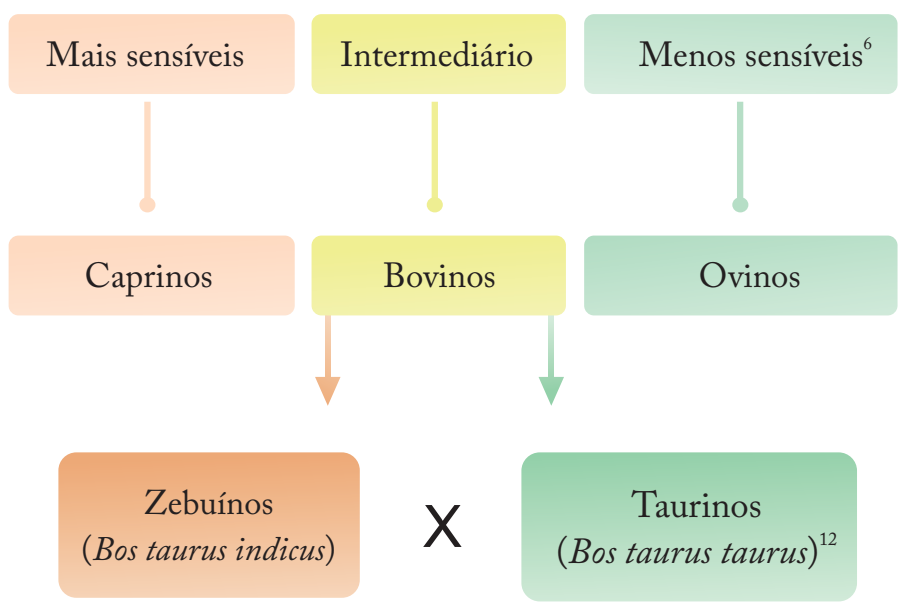


Os efeitos cardiovasculares causados pela xilazina incluem bradicardia, bloqueio atrioventricular de segundo grau, hipotensão e redução do débito cardíaco, os quais são geralmente suportados por animais hígidos, mas contraindicam o emprego deste fármaco em animais portadores de alterações cardiocirculatórias ${ }^{3}$.

No sistema respiratório, a xilazina causa depressão dose-dependente, com hipoxemia e hipercapnia, a qual é agravada pelo decúbito ${ }^{13}$. Além disso, em ovinos pode desencadear edema pulmonar, devido à lesão no endotélio capilar pulmonar, com consequente hemorragia intra-alveolar, ativação de macrófagos intravasculares e edema intersticial e alveolar, alterações notadas a partir de 3 minutos após a administração IV ${ }^{14}$.

A xilazina não deve ser utilizada em fêmeas que estejam no terço final da gestação ${ }^{2}$, devido à contração uterina que este fármaco provoca, a qual, aliada ao aumento da resistência na artéria uterina e à bradicardia, reduz a circulação sanguínea uterina e o fornecimento de oxigênio e nutrientes ao(s) feto(s) $)^{9,15}$.

A motilidade gastrointestinal é deprimida pela xilazina, o que pode resultar em timpanismo ruminal ${ }^{3}$. Da mesma forma, a liberação de insulina também é reduzida, causando hiperglicemia ${ }^{13,16}$, que aumenta a produção de urina. Assim, deve-se evitar o uso deste fármaco em animais com comprometimento da função renal e/ou obstrução uretral.

A dose de xilazina normalmente empregada varia de 0,05 a 0,3 $\mathrm{mg} / \mathrm{kg}$ para ovinos e bovinos e de 0,02 a $0,1 \mathrm{mg} / \mathrm{kg}$ para caprinos ${ }^{3}$. A latência é curta $(2 \mathrm{a}$ 5 minutos) e o efeito sedativo dura de 30 a 60 minutos. Embora o fármaco possa ser administrado pelas vias IV, SC ou IM, as doses mais elevadas não devem ser empregadas pela via IV, para evitar a alterações bruscas dos parâmetros fisiológicos do paciente.

Salienta-se que a sedação causada pela xilazina é dose-dependente e o estresse do paciente no momento da administração interfere no efeito final, com isso, animais tranquilos requerem menores doses e animais estressados necessitam de doses mais elevadas e, em algumas ocasiões, podem não apresentar sedação adequada ${ }^{5}$. Deve-se sempre considerar esta informação no momento da escolha da dose a ser administrada, principalmente se o decúbito não é desejado.

Os efeitos da xilazina podem ser revertidos com a administração de um antagonista alfa- 2 adrenérgico, sendo os mais empregados o atipamezole, ioimbina e tolazolina, nas doses de 0,02 a 0,1 mg/kg, 0,12 a 0,25 $\mathrm{mg} / \mathrm{kg}$ e 0,5 a $2 \mathrm{mg} / \mathrm{kg}$, respectivamente ${ }^{2}$. A via de administração mais recomendada é a IM, para evitar a ocorrência de efeitos adversos como excitação e taquicardia. Caso seja necessário o emprego da via IV, deve-se empregar uma dose reduzida e a administração deve ser feita lentamente ${ }^{3}$.

\section{- Detomidina}

A detomidina é um fármaco agonista alfa-2 adrenérgico empregado inicialmente apenas em equídeos, mas que também promove sedação, miorrelaxamento e analgesia em ruminantes. É considerada mais potente que a xilazina e os seus efeitos em bovinos, ovinos e caprinos são similares aos já relatados para esta, embora existam algumas diferenças, como:

- Aumento da pressão arterial, por 5 a 10 minutos, que antecede a hipotensão;

- Analgesia mais pronunciada do que a causada pelaxilazina ${ }^{18}$;

- Não causa contração uterina em fêmeas ges$\operatorname{tantes}^{19,20}$;

- Em ovinos, a redução da frequência respiratória após a administração da detomidina é mais duradoura do que a da xilazina, podendo durar até 90 minutos, embora ocorra um aumento deste parâmetro previamente ao declínio;

- Hiperglicemia mais pronunciada com o emprego da detomidina do que da xilazina ${ }^{21}$.

Da mesma forma que a xilazina, os efeitos da 
detomidina são dose-dependentes e a recomendação posológica em bovinos, ovinos e caprinos é de 3 a 30 $\mu \mathrm{g} / \mathrm{kg}$, pelas vias IV, SC ou $\mathrm{IM}^{3}$. Quando administrada pela via IV os efeitos iniciam em 2 a 3 minutos e a duração da sedação varia de 45 a 90 minutos. Doses maiores que $20 \mu \mathrm{g} / \mathrm{kg}$ produzem analgesia moderada, mas são mais propensas a causar decúbito, especialmente pela via $\mathrm{IV}^{22}$. Administrada em ovinos, em bolus de $20 \mu \mathrm{g} / \mathrm{kg}$ seguido por infusão intravenosa contínua na dose de 60 $\mu \mathrm{g} / \mathrm{kg} / \mathrm{h}$, durante 60 minutos, a detomidina promoveu sedação satisfatória sem efeitos cardiorrespiratórios significativos, com recuperação rápida e de alta qualidade $^{23}$.

Os efeitos da detomidina podem ser revertidos com a administração de atipamezole, ioimbina ou tolazolina, nas mesmas doses já citadas para antagonizar a xilazina.

\section{- Dexmedetomidina}

A dexmedetomidina é o fármaco agonista alfa2 adrenérgico mais recentemente introduzido no comércio brasileiro. É recomendado pelo fabricante apenas para uso em cães e gatos, mas alguns estudos têm demonstrado bons resultados também em ruminantes, embora o elevado custo torne seu emprego menos frequente na rotina clínica destas espécies. É extremamente seletiva para os receptores alfa-2 adrenérgicos e é considerada o fármaco mais potente deste grupo, com relação à sedação e, sobretudo, à analgesia $^{24}$.

\begin{tabular}{|c|c|}
\hline Agonista $\alpha 2$-adrenérgico & Relação $\alpha 2: \alpha 1$ \\
\hline Dexmedetomidina & $1.620: 1$ \\
\hline Detomidina & $260: 1$ \\
\hline Xilazina & $160: 1$ \\
\hline & \\
\hline & Sedação \\
\hline
\end{tabular}

O efeito adverso mais comumente descrito é a bradicardia ${ }^{25-29}$, porém podem ocorrer também aumento da pressão arterial, resistência vascular periférica, pressão venosa central ${ }^{29}$, pressão parcial do gás carbônico $\left(\mathrm{PaCO}_{2}\right)$ e do $\mathrm{pH}$ arterial ${ }^{26}$ e redução do débito cardíaco ${ }^{29}, \mathrm{PaO}_{2}$, temperatura corpórea ${ }^{26}$ e motilidade ruminal $^{27}$. Salivação, midríase, micção, bruxismo ${ }^{26} \mathrm{e}$ hiperglicemia ${ }^{28}$ também foram descritos.

Apesar de alguns estudos não constatarem alterações na função respiratória ${ }^{25,27,28}$, em ovinos, modo similar ao já citado para a xilazina ${ }^{14}$, a dexmedetomidina pode causar edema pulmonar agudo, com congestão capilar pulmonar difusa, perda da integridade endotelial, com extravasamento de proteínas e eritrócitos, imediatamente após a sua administração $I^{30}$.

As doses usuais da dexmedetomidina variam de 1 a $5 \mu \mathrm{g} / \mathrm{kg}$, pelas vias IV ou IM ${ }^{25-28}$. A latência é de cerca de 3 minutos e o efeito sedativo máximo dura entre 30 e 80 minutos $^{25-27,29}$. Em ovelhas prenhes (90 dias de gestação) a administração da dose de $1 \mu \mathrm{g} / \mathrm{kg}$, seguida de infusão intravenosa contínua na dose de 1 $\mu \mathrm{g} / \mathrm{kg} /$ hora, durante 3 horas, gerou bradicardia, sem alteração na pressão arterial nem na função respiratória na mãe e não alterou os parâmetros fisiológicos do feto. Ocorreu hiperglicemia tanto na mãe quanto no feto. A sedação foi profunda e iniciou-se poucos minutos após o início da infusão e perdurou até 60 minutos após o seu término ${ }^{28}$.

Os efeitos da dexmedetomidina podem ser revertidos com a administração de atipamezole, ioimbina ou tolazolina, nas mesmas doses já citadas para antagonizar a xilazina.

$\mathrm{Na}$ Tabela 1 são apresentadas as doses recomendadas, vias de administração, períodos de latência e de duração dos efeitos e antagonistas, dos fármacos comumente empregados na tranquilização/sedação de ruminantes. 
Tabela 1: Doses, vias de administração, períodos de latência e de duração dos efeitos (após administração intravenosa) e fármacos reversores, dos tranquilizantes/sedativos mais comumente utilizados de ruminantes.

\begin{tabular}{|c|c|c|c|c|c|}
\hline Fármaco & Doses & Via Administração & Latência (IV) & Duração (IV) & Reversor \\
\hline Acepromazina & 0,03 a $0,1 \mathrm{mg} / \mathrm{kg}$ & SC, IM ou IV & 15 minutos & Até 6 horas & - \\
\hline Diazepam & 0,2 a 0,5 mg/kg & $\begin{array}{c}\text { IV (preferencial), IM } \\
\text { ou SC }\end{array}$ & \multirow[t]{2}{*}{3 a 5 minutos } & \multirow[t]{2}{*}{20 a 30 minutos } & \multirow{2}{*}{$\begin{array}{l}\text { Flumazenil (0,01 a } \\
0,02 \mathrm{mg} / \mathrm{kg}) \text { IV }\end{array}$} \\
\hline Midazolam & 0,1 a 0,6 mg/kg & SC, IM ou IV & & & \\
\hline Xilazina & $\begin{array}{c}0,05 \text { a } 0,3 \mathrm{mg} / \mathrm{kg} \\
\text { (ovinos e bovinos) } \\
0,02 \text { a 0,1 mg/kg } \\
\text { (caprinos) }^{3}\end{array}$ & $\begin{array}{l}\text { SC, IM ou IV (evitar } \\
\text { altas doses) }\end{array}$ & 2 a 5 minutos & 30 a 60 minutos & \multirow{3}{*}{$\begin{array}{c}\text { Atipamezole } \\
(0,02 \text { a } 0,1 \mathrm{mg} / \mathrm{kg}) \\
\text { loimbina } \\
\text { (0,12 a } 0,25 \mathrm{mg} / \mathrm{kg}) \\
\text { ou Tolazolina } \\
\text { (0,5 a } 2 \mathrm{mg} / \mathrm{kg}) \\
\text { IM ou IV }\end{array}$} \\
\hline Detomidina & 3 а $30 \mu \mathrm{g} / \mathrm{kg}$ & SC, IM ou IV & 2 a 3 minutos & 45 a 90 minutos & \\
\hline Dexmedetomidina & 1 a $5 \mu \mathrm{g} / \mathrm{kg}$ & IM ou IV & 3 minutos & 30 e 80 minutos & \\
\hline
\end{tabular}

\section{ANESTESIA LOCAL}

A anestesia local é frequentemente empregada em animais de produção pelos benefícios que proporciona, especialmente por permitir a realização de intervenções cruentas com o paciente consciente e em estação, situação de singular valia para ruminantes, que são animais susceptíveis a complicações digestivas relacionadas ao decúbito, como também para o cirurgião, que terá posição no ato cirúrgico mais confortável. Os anestésicos locais promovem bloqueio reversível dos canais de sódio, impedindo a geração e a propagação dos impulsos nervosos sensitivos e motores. São usados para anestesia local ou regional, seja como único fármaco ou compondo um protocolo anestésico, uma vez que atenuam a quantidade de anestésicos gerais exigida, com promoção de maior estabilidade cardiorrespiratória ${ }^{31}$.

Os anestésicos locais são considerados bases fracas e por este motivo quando administrados em meios ácidos, ou seja, regiões inflamadas ou infeccionadas, sua capacidade de distribuição é suprimida, já que nestes casos a forma neutra ou não ionizada (forma ativa) não é produzida (ou o é em quantidade mínima), o que impede/dificulta a eficácia do bloqueio anestésico. Como alternativa, pode-se realizar a infiltração do anestésico em uma área afastada da inflamada, ou optar por um bloqueio perineural, dos nervos que inervam a região a ser manipulada. Como o principal fator é a dificuldade em dissociação iônica em meio ácido, também se torna viável a elevação do $\mathrm{pH}$ do meio, pela adição de bicarbonato de sódio $\left(\mathrm{NaHCO}_{3}\right)$ à solução anestésica local na proporção de $0,3 \mathrm{~mL}$ de $\mathrm{NaHCO}_{3} 8,4 \%$ em $10 \mathrm{~mL}$, resultando em aumento das moléculas neu$\operatorname{tras}^{32}$.

Os fármacos anestésicos locais mais utilizados nos ruminantes são a lidocaína (1\% ou 2\%) e a bupivacaína $(0,25 \%$ ou $0,5 \%)$ com ou sem vasoconstrictor ${ }^{31}$. Outros fármacos têm seu uso com menor frequência, como a ropivacaína, principalmente quando se busca maior seletividade de bloqueio em nervos sensitivos ${ }^{33} \mathrm{e}$ a levobupivacaína ${ }^{34}$ proporcionando maior tempo de bloqueio, similar à bupivacaína, contudo com maior segurança quanto à neuro e cardiotoxicidade ${ }^{35}$.

A rápida elevação da concentração plasmática é um dos principais fatores envolvidos na intoxicação por anestésicos locais, decorrente da administração inadvertida destes fármacos pela via IV ou de sobredoses 
administradas, alta absorção sistêmica e distribuição tecidual. Em ratos a administração de bupivacaína, levobupivacaína e lidocaína no nervo isquiático, causou alterações histopatológicas e deficiência motora, com frequência e gravidade variadas, dano neural provavelmente resultante do trauma mecânico pela agulha, efeitos químicos do anestésico local, isquemia ou de uma combinação destes fatores ${ }^{36}$. Em ovinos adultos conscientes as doses intravenosas de lidocaína e bupivacaína que desencadeiam atividade convulsiva são 5,8 $\mathrm{mg} / \mathrm{kg}$ e de 4,2 a $4,4 \mathrm{mg} / \mathrm{kg}$, respectivamente, ao passo que hipotensão e colapso cardiovascular ocorrem após doses de 31 a 57 mg/kg, para a lidocaína, e de 8,3 a 9,2 $\mathrm{mg} / \mathrm{kg}$, para a bupivacaína ${ }^{37,38}$.

A lidocaína na concentração de $2 \%$ é o anestésico local mais utilizado em ruminantes, por sua eficá- cia, baixo custo e baixo risco de toxicidade ${ }^{31}$, sendo as técnicas de anestesia infiltrativa superficial e profunda na fossa paralombar, anestesia epidural caudal ou cranial e bloqueios perineurais (nervo cornual e no funículo espermático) as mais comumente empregadas na rotina clínica anestesiológica de bovinos e pequenos ruminantes.

\section{ANESTESIA DA CABEÇA}

Dentre os bloqueios regionais na região da cabeça, em ruminantes, os mais empregados são para realização de descorna, enucleação ocular, exérese de neoplasias e correção de entrópio ou ectrópio.

Para a realização da descorna em bovinos, devese bloquear o suprimento nervoso sensitivo que englo-

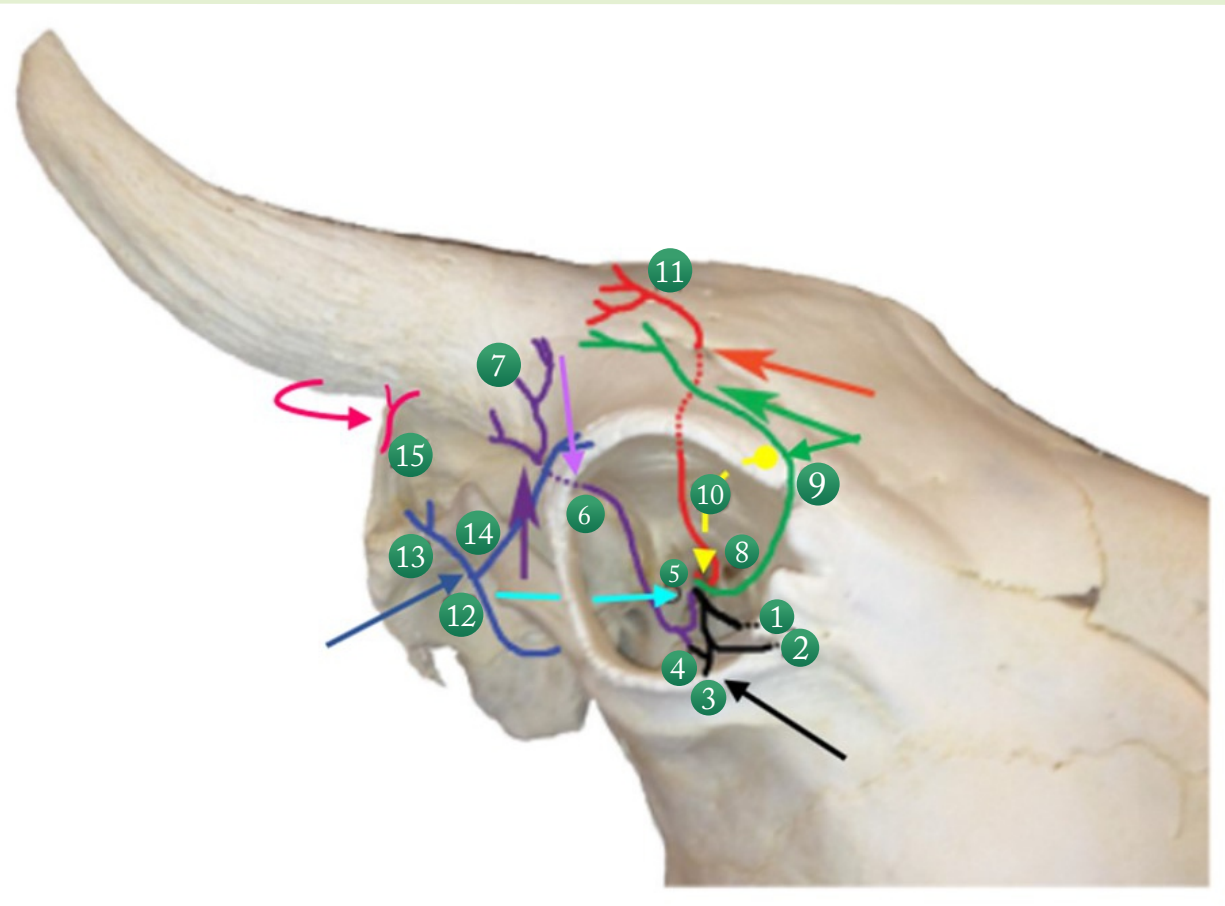

Figura 1. Inervações emergentes da órbita e ramos do segundo nervo cervical. Locais para bloqueio, indicado pelas setas: nervo supraorbitário (seta vermelha), nervo infratroclear (seta verde), nervo cornual (seta roxa), ramo do segundo nervo cervical (seta rosa), nervo lacrimal (seta lilás), nervo zigomático (seta preta), nervo auriculopalpebral (seta azul), bloqueio de Peterson (seta azul ciano), bloqueio retrobulbal por acesso na comissura medial (seta pontilhada amarela). (1) Nervo maxilar (preto),(2) ramo zigomaticofacial, (3) nervo zigomático, (4) ramo comunicante do nervo zigomático para o nervo lacrimal, (5) nervo lacrimal (roxo), (6) ramo zigomaticotemporal, (7) ramo cornual,(8) nervo nasociliar (verde),(9) nervo infratroclear,(10) nervo frontal (vermelho), (11) nervo supraorbitário, (12) nervo auriculopalpebral (azul),(13) ramo auricular rostral, (14) ramo zigomático e (15) ramo do segundo nervo cervical (rosa) (Fonte: Adaptada de Valverde e Sinclair ${ }^{40}$ ). 
ba o nervo cornual, nervos supraorbitário e infratroclear, todos originários do ramo oftálmico do nervo trigêmeo (Figura 1). Na maioria dos animais apenas o bloqueio do nervo cornual já se faz suficiente para realização da descorna, para o qual se emprega 5 a $10 \mathrm{~mL}$ de anestésico local por via SC, na depressão localizada na linha média imaginária entre o canto lateral do olho e a base do corno. Importante atentar-se que sempre próximo a um nervo há artéria e veia, ressaltando-se a necessidade de certificar que a administração não está sendo intravenosa. Em alguns bovinos adultos pode-se observar a necessidade do bloqueio adicional infiltrativo superficial ao redor do corno, utilizando 10 a $20 \mathrm{~mL}$, para bloquear os ramos cutâneos cervicais que inervam a porção caudal da base cornual ${ }^{39}$.

Para bloqueio dos nervos supraorbitário e infratroclear (Figura 1) deve-se usar uma agulha 22 a $21 \mathrm{G}$ e injetar $5 \mathrm{~mL}$ do anestésico local, seja em uma única abordagem, já que os ramos do nervo infratroclear seguem a mesma direção dos ramos do supraorbitário, ou individualmente, sendo o ponto do infratroclear 2 a $3 \mathrm{~cm}$ medial do aspecto dorsal da margem da órbita. Já o nervo supraorbitário emerge do forame supraorbitário, local de bloqueio deste nervo, que pode ser localizado no terço médio da linha imaginária traçada entre o processo supraorbitário e a borda medial da base do chifre $^{39}$.

Os pequenos ruminantes apresentam anatomia neuronal do corno similar ao bovino, devendo-se bloquear os nervos cornual e supraorbitário simultaneamente. Para tal, traça-se uma linha imaginária entre o canto lateral do olho e a borda lateral da base do chifre, em sua porção medial e, com uma agulha $22 \mathrm{G}$, injeta-se 2 a $3 \mathrm{~mL}$ de anestésico local ${ }^{40,41}$.

Nas intervenções do globo ocular e seus anexos busca-se bloquear os nervos que emergem dos forames orbitorrotundo e óptico, promovendo geralmente dessensibilização sensitiva e motora. Em bovinos a anestesia do olho é exigida mais frequentemente para a cirurgia de enucleação, e as técnicas mais utilizadas são o bloqueio retrobulbar e o bloqueio de Peterson ${ }^{42}$.

$\mathrm{O}$ bloqueio retrobulbar pode ser empregado por acesso na comissura medial (Figuras 1 e 2A), no canto lateral ${ }^{43}$ ou pela técnica dos quatro pontos, esta com maior probabilidade de difusão do anestésico junto dos nervos orbitários ${ }^{41}$. As estruturas a serem dessensibilizadas, músculos orbiculares, globo ocular e conjuntiva, assim são por inativação dos nervos óptico, oculomotor, troclear, ramos do trigêmeo e abducente ${ }^{40}$. Para tal usa-se uma agulha de calibre 18 ou 20G, previ-
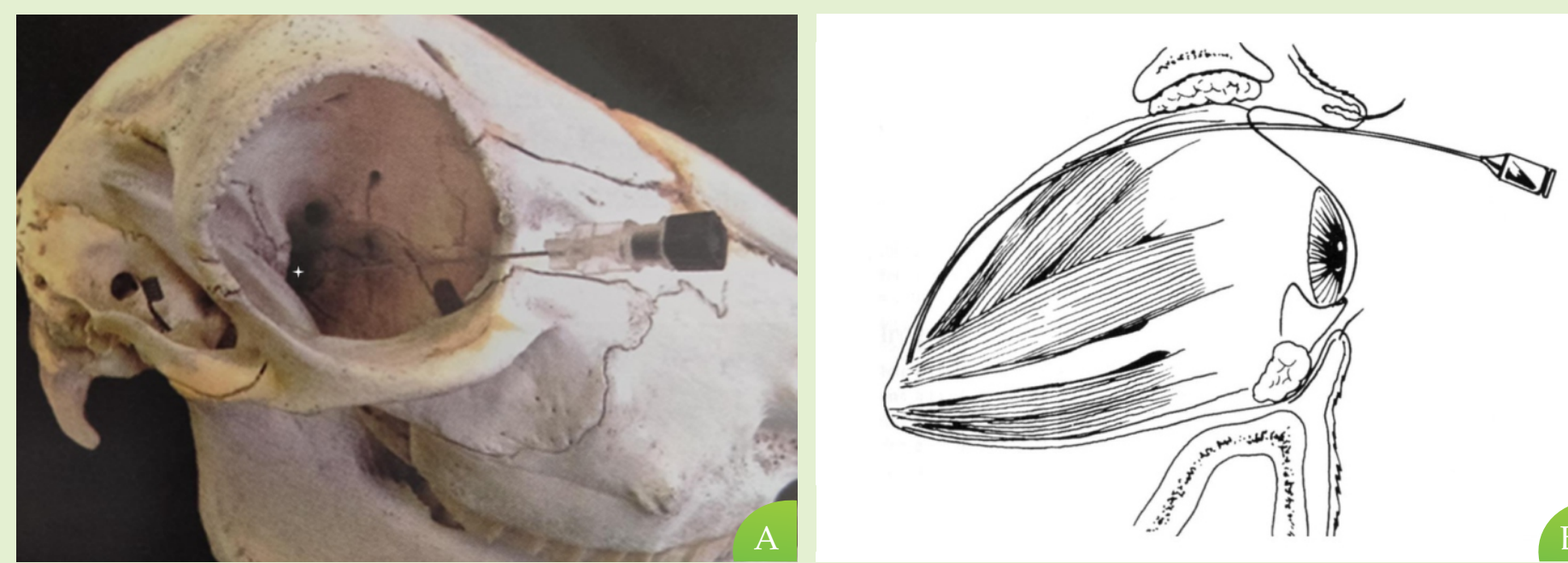

Figura 2: Posicionamento da agulha para execução do bloqueio retrobulbar. (A) Acesso pela comissura medial do olho em crânio de ovino (Fonte: Santos et al. ${ }^{43}$ ). (B) Ilustração da agulha curva, previamente moldada, para que possa acompanhar anatomia da órbita (Fonte: Skarda e Tranquili ${ }^{44}$. 

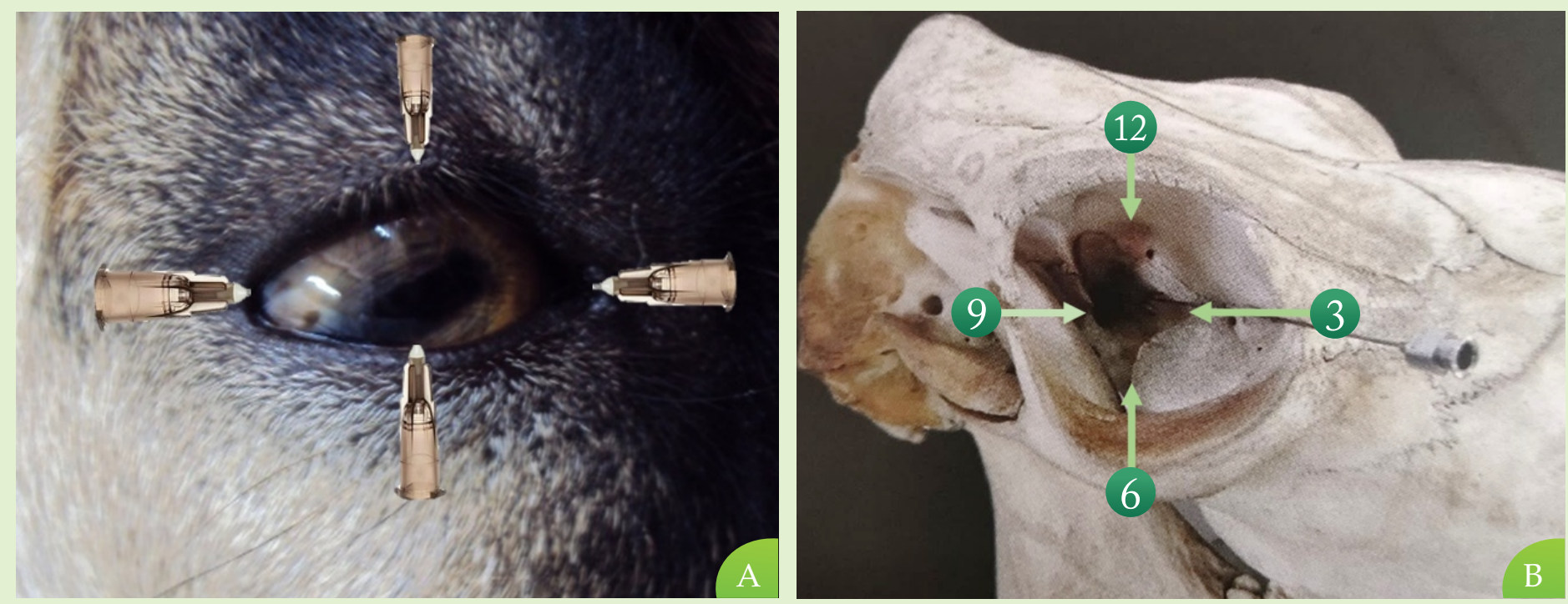

Figura 3. Pontos demonstrativos do posicionamento das agulhas para bloqueio retrobulbar em quatro pontos em (A) caprino e (B) crânio de bovino, com indicação dos pontos: dorsal (12), medial (3), ventral (6) e lateral (9) (Fonte: Adaptada de Santos et al. ${ }^{43}$ ).

amente moldada em formato curvo para que possa acompanhar anatomia da órbita (Figura 2B). Na técnica dos quatro pontos, as punções ocorrerão nas posições de 12, 3, 6 e 9 horas (Figura 3), a uma profundidade de 7 a $9 \mathrm{~cm}$ (em bovinos adultos), administrando de 5 a $10 \mathrm{~mL}$ do fármaco, de preferência com vasoconstrictor, em cada ponto. No caso do bloqueio unitário utilizar até no máximo $20 \mathrm{~mL}^{43}$. Deve-se ter prudência quanto ao volume, à profundidade e ao tamanho da agulha, conforme a espécie que se está trabalhando. A técnica é confirmada por proptose do olho anestesiado.
O Bloqueio de Peterson (Figuras 1 e 4) é outra possibilidade para bloqueio do olho, considerado mais complexo que os anteriores ${ }^{42}$, porém com menor risco de lesão ao globo ocular e indicado principalmente na existência de processo inflamatório intenso ou infeccioso, pois nestes casos a capacidade de ativação do anestésico local é diminuída, conforme já mencionado.

Para executar este bloqueio deve-se introduzir a agulha (12 a $10 \mathrm{~cm}$ ) no espaço entre a margem rostral do processo coronoide da mandíbula e caudalmente à incisura do encontro do arco zigomático e o processo
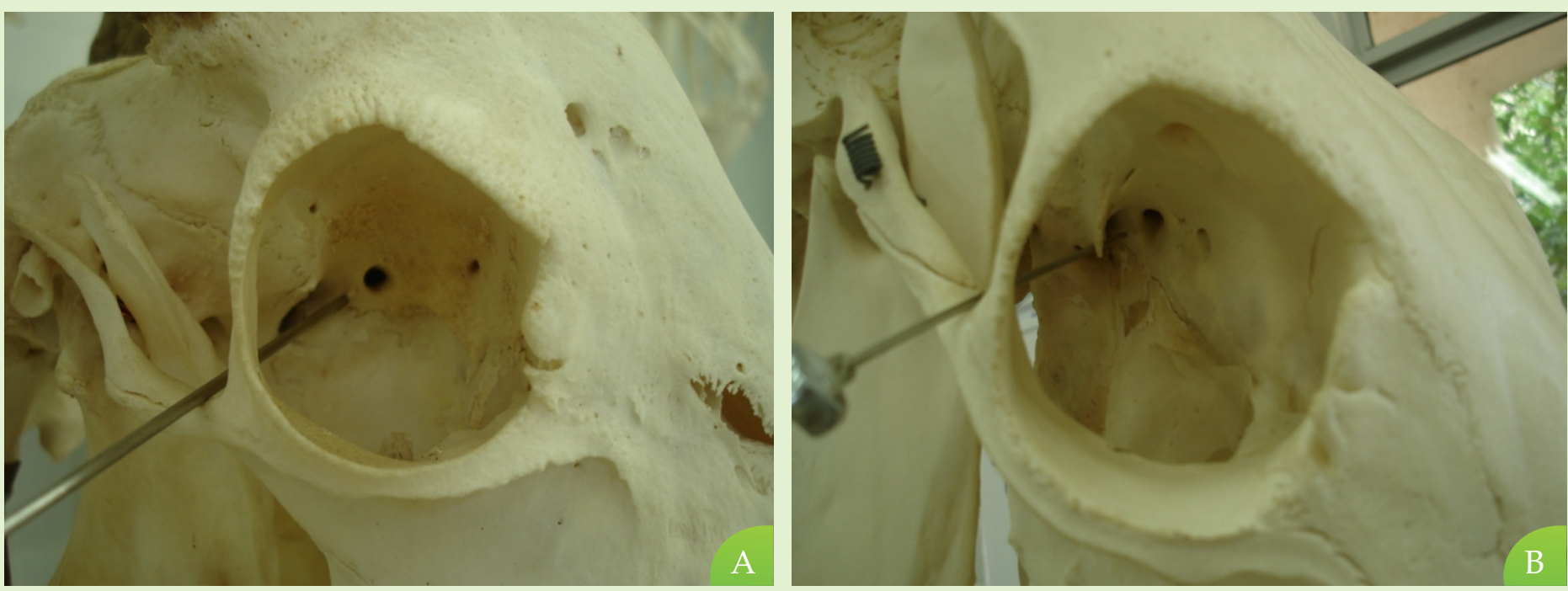

Figura 4. Posicionamento da agulha para realização do bloqueio de Peterson em crânio de (A) ovino e de (B) bovino (Fonte: HVU/UFCG). 
supraorbitário, conduzindo-a discretamente no sentido ventral e posterior, até tocar o fundo da órbita, onde injeta-se o anestésico local $(15 \text { a } 20 \mathrm{~mL})^{40,42,43}$. Esta técnica é similarmente realizada em pequenos ruminantes e bezerros, devendo-se apenas ajustar o volume administrado (3 a $4 \mathrm{~mL}$ ) e o tamanho da agulha $(6,3 \mathrm{~cm})^{40}$. Desta forma, se conseguirá bloquear os nervos oftálmico, maxilar e mandibular, que são ramos do nervo trigêmeo e nervos troclear, abducente e oculomotor, o produz anestesia e imobilização do globo ocular.

Para que se consiga realizar intervenções nas pálpebras se faz necessário bloquear os nervos supraorbitário, infratroclear, lacrimal e zigomático. Os bloqueios do supraorbitário e do infratroclear já foram comentados anteriormente. Para o bloqueio dos nervos lacrimal e zigomático a agulha deve ser posicionada no espaço subcutâneo no canto lateral da pálpebra superior e na região ventral da órbita na pálpebra inferior, respectivamente (Figura 1). Para os quatro bloqueios emprega-se uma agulha 22 ou $21 \mathrm{G}$ e um volume de anestésico local de 3 a $5 \mathrm{~mL}$. Quando se almeja apenas acinesia da pálpebra superior, pode-se bloquear o nervo auriculopalpebral (Figuras 1 e 5), administrando $5 \mathrm{~mL}$ do fármaco por via subcutânea, no ponto médio da linha imaginária traçada entre o canto lateral do olho e a base da orelha ${ }^{40}$.

Nos procedimentos que necessitem de dessensibilização das regiões mandibular e maxilar, os nervos mentual, mandibular, infraorbitário e maxilar podem ser bloqueados, na dependência de qual área será manipulada. Os bloqueios dos nervos mentual e infraorbitário são mais simples de executar pois emergem dos foramens homônimos, que são facilmente palpáveis.

Para o bloqueio, insere-se a agulha (geralmente $25 \times 30 \mathrm{~mm}$ ) o mais próximo possível do forâmen e realiza-se a deposição subcutânea de 3 a $10 \mathrm{~mL}$ do anestésico local escolhido. A área anestesiada após o bloqueio do nervo mentual corresponde ao lábio inferior e gengivas e dentes incisivos mandibulares do lado correspondente ao nervo bloqueado. Já a anestesia do nervo infraorbitário dessensibiliza a narina, o lábio superior, a mucosa oral e a porção rostral do palato duro ipsilaterais ao nervo bloqueado (Figura 6) ${ }^{43}$.

Os bloqueios dos nervos mandibular e maxilar são tidos como bloqueios cegos, necessitando de uma agulha $100 \times 18 \mathrm{G}$, ou mais longa, e um volume de até $20 \mathrm{~mL}$ do anestésico local, conforme o porte do animal. Para o nervo mandibular insere-se a agulha pela face medial da mandíbula, transcutânea, até a intersecção de duas linhas imaginárias: uma que margeia o canto lateral do olho e outra traçada sobre a arcada dentária molar mandibular (Figura 6) ${ }^{43}$.

O bloqueio do nervo maxilar é mais complicado e melindroso, pois traz maiores riscos em sua execução, tais como perfuração do globo ocular, punção da artéria maxilar ou lesão do nervo. Em ruminantes é considerado de baixa aplicabilidade, porém, quando necessário, é obtido pela administração de $20 \mathrm{~mL}$ do anestésico local (em um bovino adulto), na fossa pterigopalatina, acessada introduzindo-se uma agulha longa no aspecto ventral da metade rostral do arco zigomático, direcionando a agulha levemente em sentido rostral ${ }^{43}$.

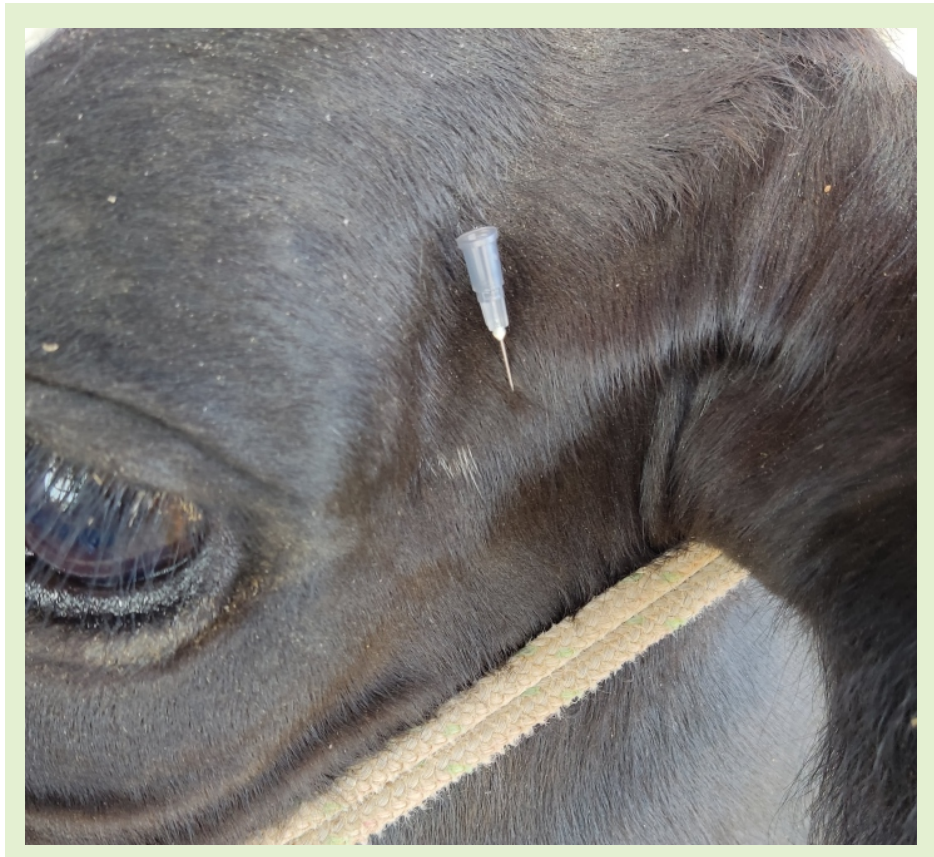

Figura 5. Posicionamento da agulha para realização do bloqueio do nervo auriculopalpebral. 


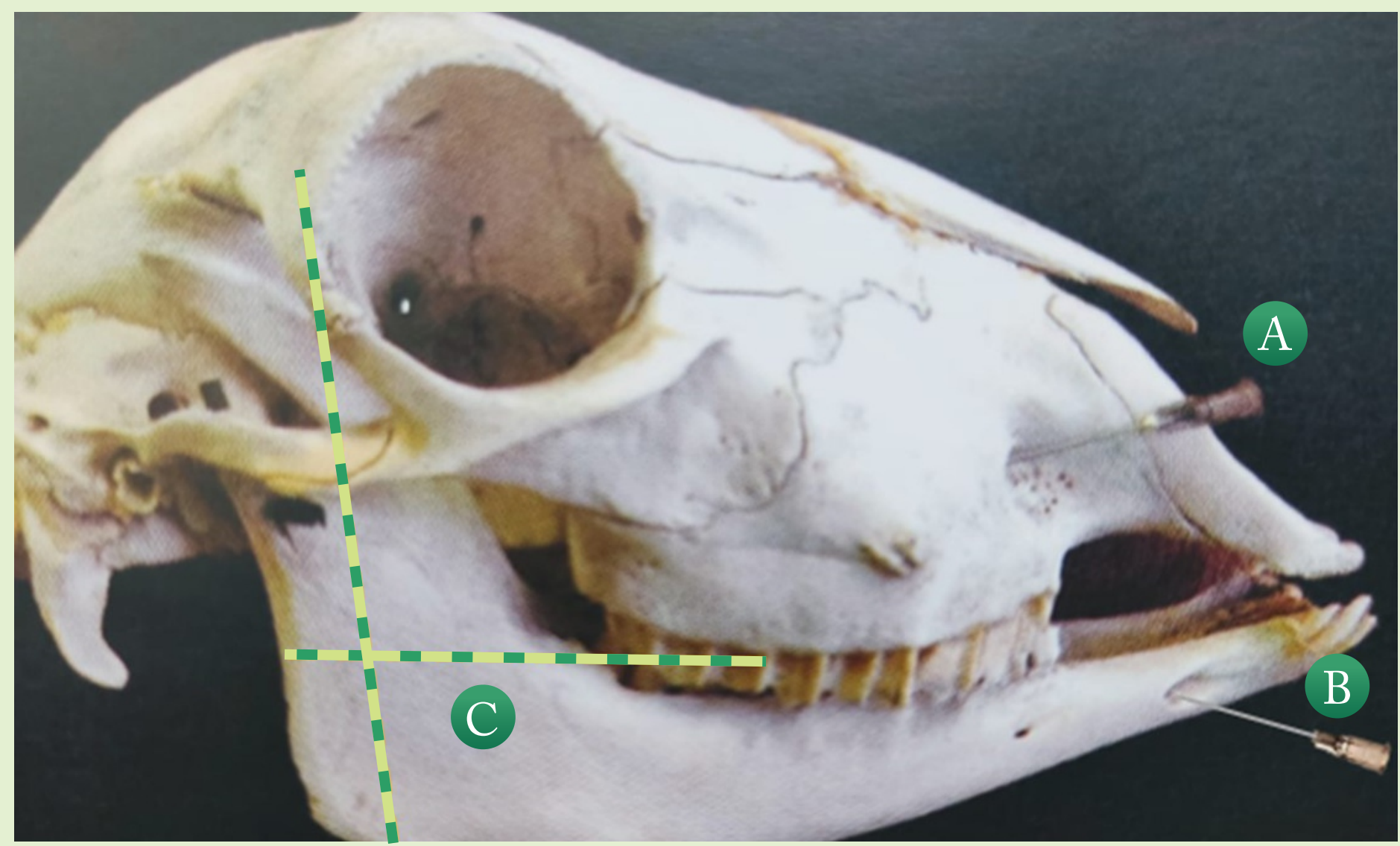

Figura 6. Posicionamento da agulha para bloqueio do (A) nervo infraorbitário e do (B) nervo mentual em crânio de ovino. (C) Localização do forame mandibular pelo encontro entre as linhas imaginárias que margeiam o canto lateral do olho e a linha sobre a arcada dentária molar mandibular (Fonte: Adaptada de Valverde e Sinclair ${ }^{40}$ ).

\section{ANESTESIA DO TRONCO}

Os procedimentos mais corriqueiros em ruminantes, envolvendo o tronco, são as laparotomias, cesariana, orquiectomias e mastectomias. Estas intervenções podem ser realizadas apenas com a utilização da anestesia local ou da associação desta com a contenção química. A execução de procedimentos cirúrgicos com o paciente ruminante em estação é favorável, pois mitiga as possibilidades de complicações digestivas e/ou mioneurais decorrentes do decúbito.

Para intervenções na fossa paralombar as técnicas de bloqueio local mais empregadas são a infiltrativa superficial e profunda em "L" invertido e a anestesia perineural paravertebral. Ambas proporcionam dessensibilização dos dermátomos inervados pelo $13^{\circ}$ nervo torácico (T13) e pelos primeiro e segundo ner- vos lombares (L1 e L2). Nos casos em que se necessita ampliar a área dessensibilizada o terceiro nervo lombar (L3) também deverá ser bloqueado, pois inerva o terço caudal do flanco abdominal e pode progredir com ramos que seguem os aspectos mais craniais do flanco ${ }^{40}$.

A técnica de anestesia local em " $L$ " invertido é simples e é realizada com a deposição do anestésico local de forma subcutânea e intramuscular, formando duas linhas que se encontram no vértice dorso-cranial, sendo uma imediatamente caudal à última costela e a outra ventral aos processos transversos das vértebras lombares (Figura 7). O volume de anestésico a ser empregado é limitado pela dose tóxica do mesmo, mas gira em torno de 20 a $30 \mathrm{~mL}$ para pequenos ruminantes adultos e de 80 a $100 \mathrm{~mL}$ para bovinos adultos. Para facilitar a execução da técnica e diminuir a necessidade de realizar várias perfurações, indica-se a utilização de 

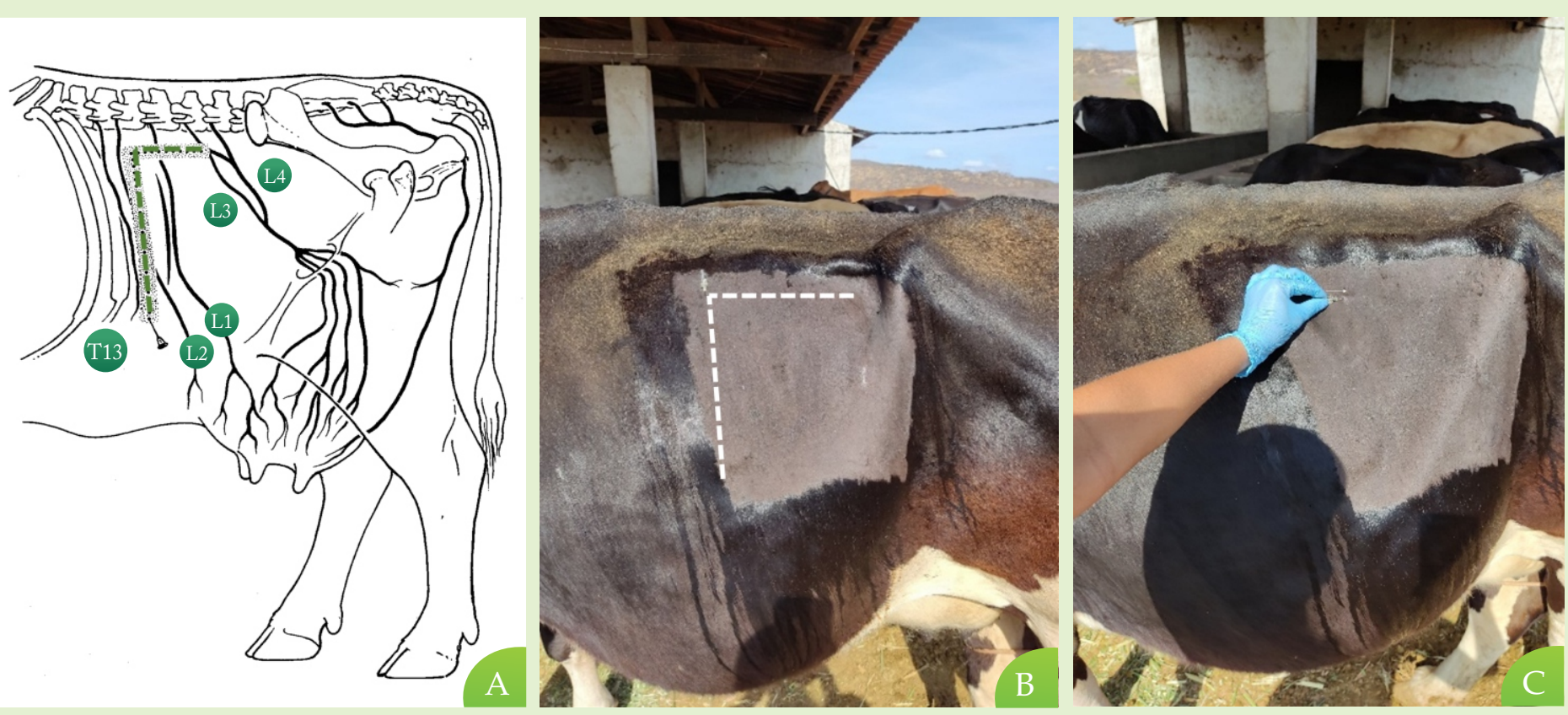

Figura 7.Técnica de anestesia local em "L" invertido. (A e B) Esquemas ilustrativos do local a ser realizado o bloqueio anestésico local infiltrativo (linhas pontilhadas) (Fonte A: Skarda; Tranquili ${ }^{44}$ ) e (C) posicionamento da agulha para realização do bloqueio na fossa paralombar esquerda de bovino.

agulhas longas e que se faça administrações do anestésico tanto no espaço subcutâneo quanto no interior dos músculos a partir de cada ponto de introdução da agulha ${ }^{40}$.

A anestesia paravertebral proximal (técnica de Farquharson, Hall ou Cambridge) e a paravertebral distal (técnica de Magda Cakala ou Cornell) (Figura 8) são possibilidades para bloquear os nervos T13, L1 e $\mathrm{L} 2^{40,41}$, os quais inervam a região dorsal da fossa paralombar. Opcionalmente pode-se bloquear também o nervo L3, porém, devido ao fato de o nervo femoral poder ter ramos originários de L3, a anestesia deste pode provocar fraqueza do membro pélvico ipsilateral

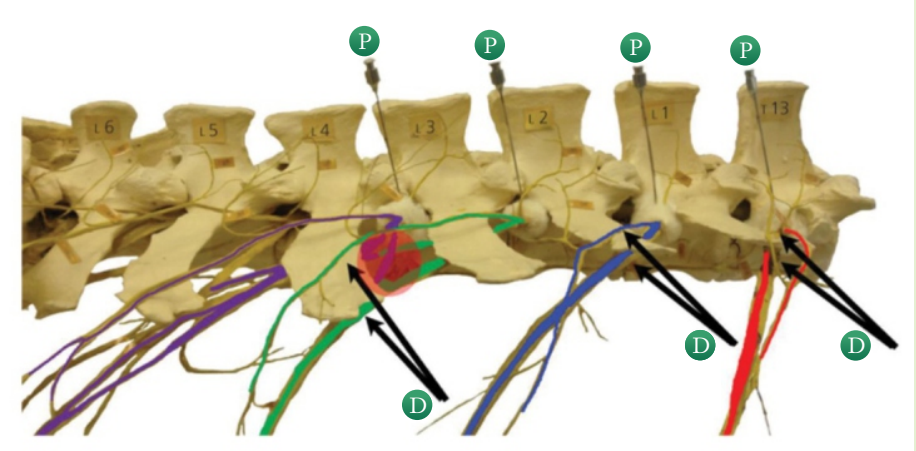

ao bloqueio ${ }^{45}$.

A técnica paravertebral proximal permite a deposição do anestésico local em proximidade com os nervos espinhais conforme emergem do canal vertebral, com bloqueio dos seus ramos dorsal e ventral. Para sua execução, identificam-se os processos transversos lombares 1 a 4 (Figura 8) e introduz-se a agulha a aproximadamente $5 \mathrm{~cm}$ da linha média dorsal em bovinos $\mathrm{e}$ $3 \mathrm{~cm}$ em pequenos ruminantes ${ }^{40}$, de forma perpendicular à coluna. Para o bloqueio do nervo T13 a agulha é inserida imediatamente cranial ao processo transverso de L1, administrando o volume de 5 a $10 \mathrm{~mL}$ de anestésico local no subcutâneo, para anestesiar o ramo dorsal,

Figura 8. Ilustração dos bloqueios paravertebral proximal (P) e distal(D) nos nervos T13,L1, L2 e L3. Os ramos dorsais são os finos e os ventrais são os mais espessos. Em destaque o encontro entre os ramos ventrais dos nervos L2 e L3, no espaço intertransverso L3 e L4 (círculo sombreado). A indicação do posicionamento dorsal e ventral da agulha para o bloqueio paravertebral distal é representado pelas setas pretas (Fonte: Valverde e Sinclair ${ }^{40}$ ). 
e depois progredindo com agulha pelo ligamento intertransverso, após o qual deposita-se 10 a $20 \mathrm{~mL}$ do anestésico local, para obter o bloqueio do ramo ventral. Este procedimento deve ser repetido imediatamente cranial aos processos transversos de L2 e L3, visando o bloqueio nos ramos dos nervos L1 e L2, respectivamente ${ }^{43}$. Em pequenos ruminantes ou bezerros, seguese a mesma técnica de bloqueio, empregando volumes de 0,5 a $1 \mathrm{~mL}$ do anestésico local para o ramo dorsal e 2 a $3 \mathrm{~mL}$ para o ventral ${ }^{40}$.

A anestesia paravertebral distal tem a mesma função da paravertebral proximal, sendo, no entanto, alterados o local de punção e a forma de administração do anestésico. Para esse bloqueio, utiliza-se a abordagem lateral ao processo transverso lombar, introduzindo a agulha, para bloqueio do nervo T13, entre T13 e L1 e conduzindo-a até a metade da distância entre a linha média dorsal e a extremidade lateral da apófise transversa de L1, tanto no sentido dorsal como ventral deste ponto, em relação à apófise transversa, para que se possa bloquear todos os ramos nervosos. Depositam-se $5 \mathrm{~mL}$ do anestésico local dorsalmente e 10 a $20 \mathrm{~mL}$ ventralmente a cada processo transverso. Como demonstrado na Figura 3, os ramos dos nervos L2 e L3 são bloqueados na borda do processo transverso da vértebra $\mathrm{L} 4$, e os ramos de L1 na borda do processo transverso da $\mathrm{L} 2^{40}$.

As anestesias paravertebrais são mais facilmente executadas em animais magros ou com escore corporal regular a bom. Em animais com escore corporal muito bom e/ou muito musculosos a identificação das estruturas anatômicas norteadoras para estes bloqueios é mais difícil, inviabilizando, em alguns casos, a execução da técnica. Uma das formas de se constatar que o bloqueio paravertebral foi eficaz é constatando a ocorrência da escoliose (desvio lateral da coluna), que se dá pela ausência de tônus muscular na antimeria bloqueada decorrente da paralisia reversível da musculatura abdominal, causada pelo anestésico local (Figura 9).
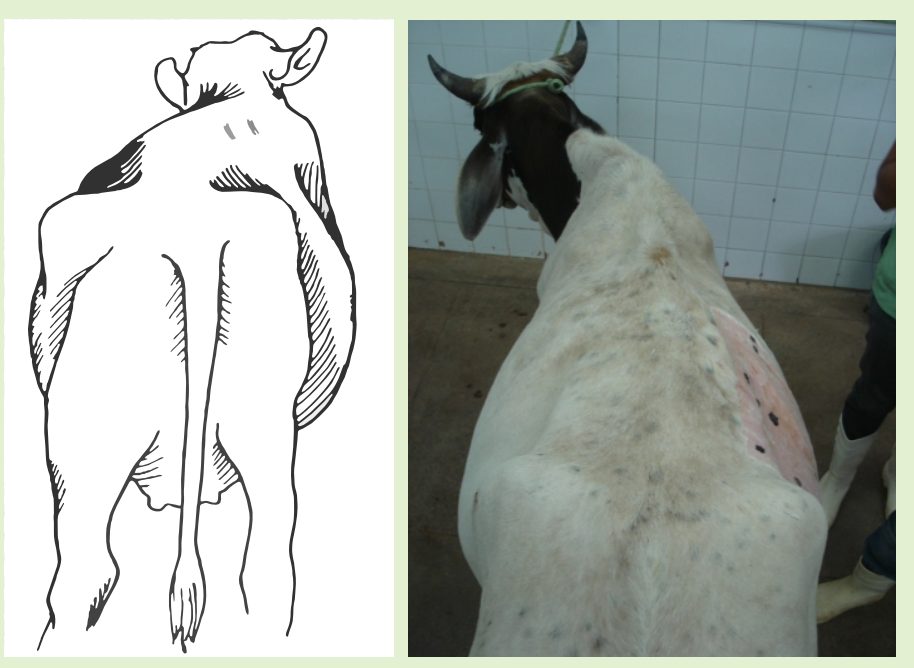

Figura 9. Demonstração da escoliose (desvio lateral da coluna) decorrente do bloqueio paravertebral. (A) Ilustração de bovino com escoliose para o lado esquerdo (Fonte: Skarda; Tranquili $^{44}$ ) e (B) bovino com escoliose para o lado direito (Fonte: HVU/UFCG).

Antes da realização de qualquer dos bloqueios para intervenção no flanco aqui citados, seja infiltrativo, perineural ou epidural, deve-se realizar tricotomia e preparação asséptica da área a ser puncionada.

A anestesia epidural, também conhecida como peridural ou extradural, consiste na deposição de um anestésico local no espaço existente entre a dura máter e o canal vertebral, visando o bloqueio dos nervos espinhais logo após a sua emergência através das meninges. Pode ser considerada cranial (anterior) ou caudal (posterior), dependendo do volume a ser administrado, e o acesso ao espaço epidural pode ser conseguido com as punções lombossacra (Figura 10), sacrococcígea ou intercoccígea $^{43}$. Para facilitar a execução da técnica epidural pode-se realizar um botão anestésico no ponto de punção, empregando com uma agulha $25 \times 7 \mathrm{~mm}$, com até $1 \mathrm{~mL}$ de lidocaína $1 \%$ ou 2\% distribuídos 50\% no espaço subcutâneo e os outros 50\% no ligamento interespinhoso, o que dessensibilizará a área a ser posteriormente puncionada por uma agulha de maior calibre.

Nos pequenos ruminantes e bezerros o emprego da anestesia epidural cranial é muito mais usual do 

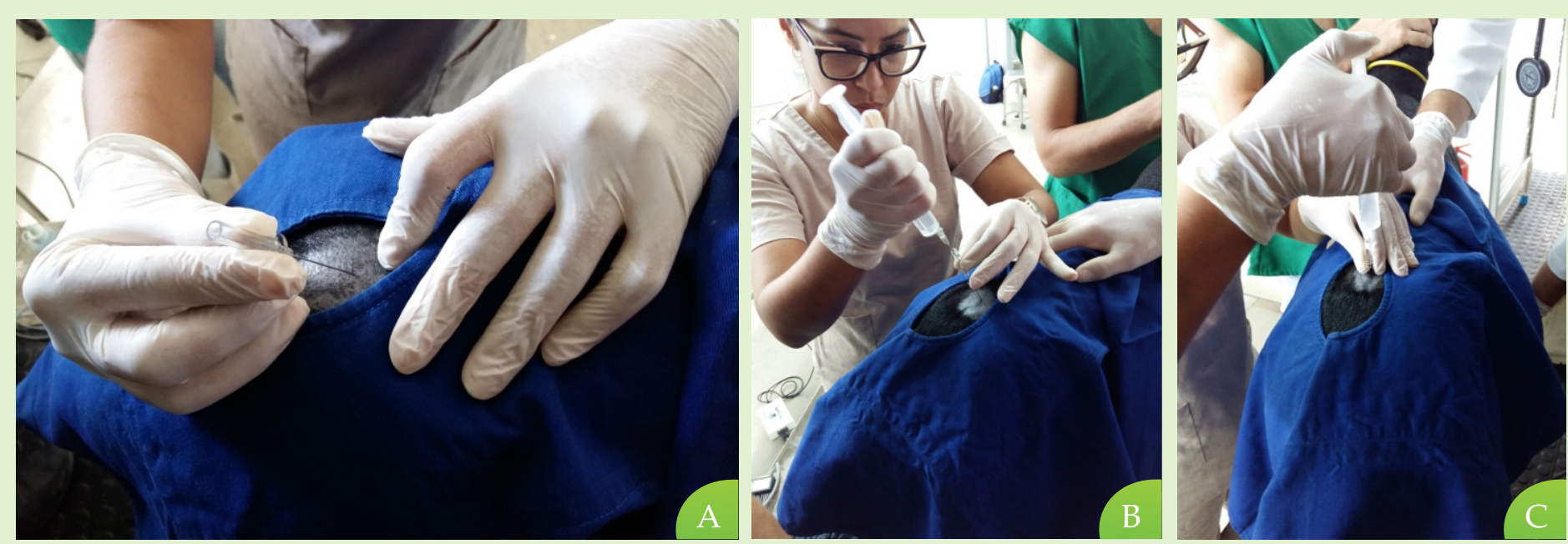

Figura 10. Sequência da técnica anestésica epidural lombossacra em ovino. (A) Introdução da agulha até o espaço subcutâneo, (B) deposição do anestésico local no canhão da agulha e (C) administração do anestésico no espaço epidural.

que em bovinos adultos. Geralmente utiliza-se uma agulha $20 \mathrm{G}$ ou $21 \mathrm{G}$ x $1 \frac{1}{2}$ e emprega-se a punção lombossacra, utilizando o anestésico local escolhido nas doses de 0,1 a 0,3 mL/ $\mathrm{kg}^{40}$. Estas doses e via de administração foram avaliadas em caprinos imediatamente após eutanásia, administrando azul de metileno para identificar a migração da substância, que teve distribuição rostral média entre L3 e L4,T13 e L1 e T10 e T11, respectivamente ${ }^{46}$. Nos bovinos adultos, para se obter bloqueio similar pela via epidural, com insensibilização do abdômen caudal e de todas as estruturas caudais, incluindo os membros pélvicos, recomendam-se volumes de anestésico local de até $150 \mathrm{~mL}(0,2$ a 0,3 $\mathrm{mL} / \mathrm{kg}$ ), com punção sacrococcígea ou intercoccígea. Contudo, esta anestesia ocasionará também bloqueio motor e sensitivo dos membros pélvicos, o que pode trazer complicações especialmente após o término da cirurgia sem a completa recuperação do tônus muscular, podendo ocasionar lesões no paciente ao tentar se movimentar ou assumir a postura quadrupedal. Comumente, dentre os anestésicos locais a lidocaína $2 \%$ e a bupivacaína $0,5 \%$ são as mais empregadas, seja isoladamente ou associados, mas a lidocaína ainda é de eleição por suas características de curta latência e duração de ação satisfatória (60 a 120 minutos) ${ }^{40}$.

A anestesia epidural caudal, com acesso sacro- coccígeo ou intercoccígeo, é mais empregada em bovinos adultos, pois apresenta maior facilidade de execução e aplicabilidade na rotina clínica cirúrgica. Nesta modalidade, a anestesia envolve a região posterior da garupa, incluindo cauda, ânus, reto, períneo, vulva e vagina. Com a movimentação da cauda em sentido dorsoventral é possível identificar os espaços intervertebrais sacrococcígeo (S5-Co1) ou intercoccígeo (Co1-Co2). Escolhido o ponto de punção, uma agulha $21 \mathrm{G}$ x $11 / 2$, é introduzida em ângulo de $80^{\circ}$ ao plano da pele até a região subcutânea, momento em que preenche-se o canhão da agulha com o fármaco a ser injetado, e em seguida progride-se com a agulha até sentir uma crepitação e maior resistência (ligamento flavum ou amarelo). Transpassado o ligamento a ponta da agulha terá atingido o espaço epidural, o que será confirmado pela aspiração do fármaco depositado no canhão da agulha, devido à pressão negativa existente no interior do espaço epidural. Outra forma de confirmar a correta posição da agulha no espaço epidural é pela ausência de resistência ao êmbolo da seringa durante a administração do fármaco ${ }^{40,43,46}$.

O volume habitual recomendado de anestésico local (lidocaína a $2 \%$, bupivacaína a $0,5 \%$, ropivacaína a 0,75\%) para injeção epidural caudal no bovino adulto é de 5 a $6 \mathrm{~mL}$ (aproximadamente $1 \mathrm{~mL} / 100 \mathrm{~kg})^{40,41}$. Volu- 
mes acima de $10 \mathrm{~mL}$ podem causar fraqueza dos membros pélvicos e decúbito, em decorrência do envolvimento dos nervos L4 a L6, que são contribuintes principais para o nervo femoral, e L5 a S2, os principais para o nervo ciático ${ }^{47}$. O início da anestesia geralmente se dá em 10 a 20 minutos, embora se evidencie flacidez da cauda em menos de 1 a 2 minutos após a administração da lidocaína a 2\%. A duração da anestesia depende do anestésico local usado.

A via epidural também é utilizada para promoção de analgesia e os fármacos mais estudados são os agonistas alfa-2 adrenérgicos e os opioides. Vários estudos evidenciaram a potencialização anestésica e analgésica quando estes fármacos são associados à lidocaína pela via epidural, contudo melhores resultados têmse observado com a utilização dos alfa-2 agonistas ${ }^{40,48-50}$. As doses de alguns fármacos empregados por esta via e com esta finalidade estão apresentadas na Tabela 2.

Para promover anestesia da região do pênis, pode-se realizar o bloqueio perineural do nervo pudendo, já que é um nervo misto, responsável pela sensibilidade do pênis e pela inervação motora do terço médio e distal do músculo retrator do pênis, sendo o terço proximal deste músculo inervado pelo nervo retal caudal. Por palpação retal é possível identificar a artéria pudenda interna que serve como referência para direcionamento da agulha, a qual deve ser introduzida na fossa isquiorretal, $5 \mathrm{~cm}$ craniolateral ao ânus, onde administra-se 15 a $20 \mathrm{~mL}$ de anestésico local, para bloquear o nervo pudendo (Figura 11). Em seguida admi- nistra-se mais $10 \mathrm{~mL}$ de anestésico, 2 a $3 \mathrm{~cm}$ caudodorsalmente em relação ao primeiro ponto de deposição, para bloqueio do nervo retal caudal. É importante lembrar que este bloqueio deve ser realizado bilateralmente e sua latência e duração dependem do fármaco utilizado ${ }^{40}$.

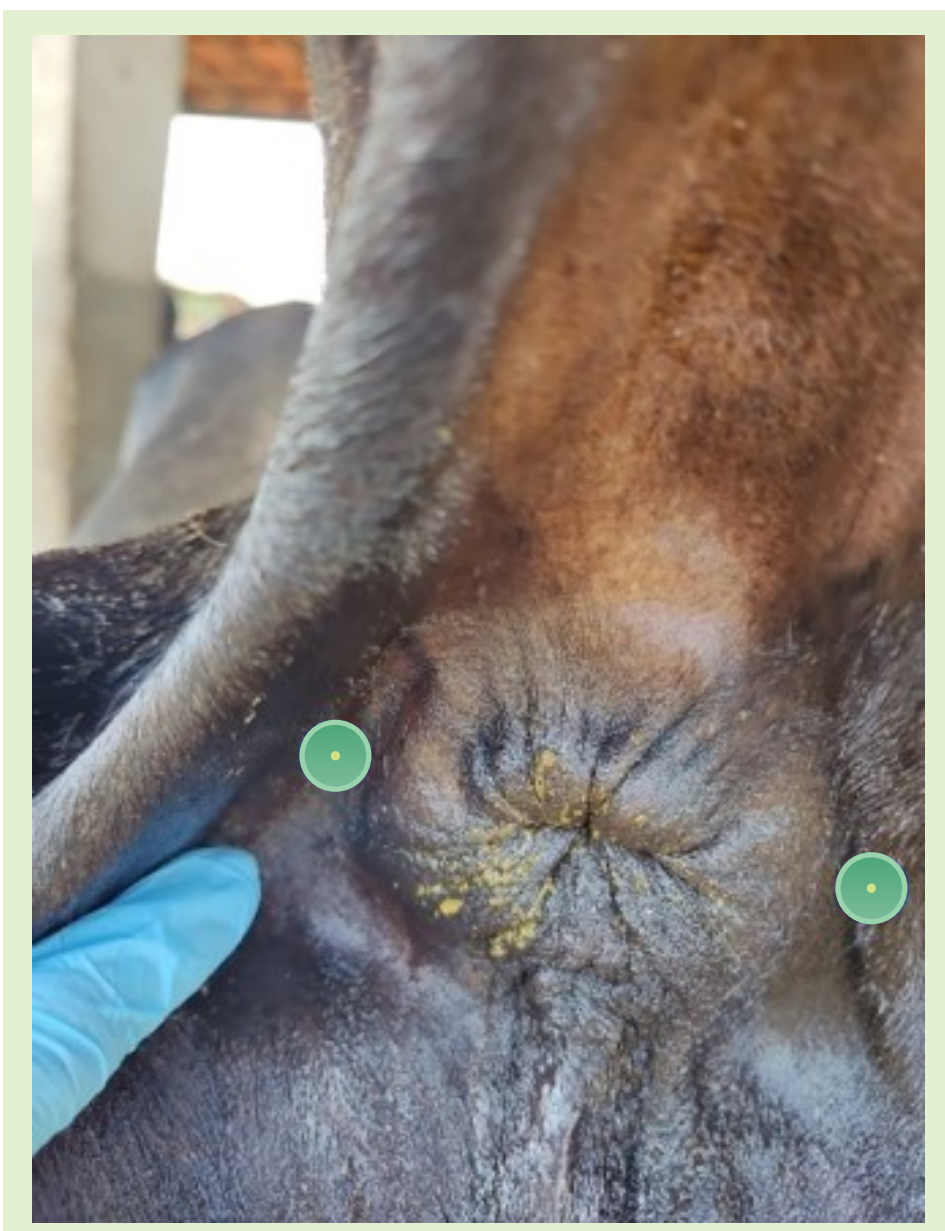

Figura 11. Locais para introdução da agulha longa (pontos verdes) para realização do bloqueio do nervo pudendo em bovino.

Tabela 2. Fármacos utilizados pela via epidural em ruminantes com intuito de analgesia.

\begin{tabular}{|c|c|c|c|c|}
\hline Fármaco & Dose $(\mathrm{mg} / \mathrm{kg})$ & Latência & Duração & Diluição ( $\mathrm{NaCl}$ 0,9\%) \\
\hline Xilazina $2 \%$ & 0,05 a 0,17 & 5 a 20 minutos & 1,5 a 2,5 horas & $5 \mathrm{~mL}$ \\
\hline Detomidina 1\% & 0,05 & 5 minutos & 1,5 horas & $7 \mathrm{~mL}$ \\
\hline Cetamina 10\% & 0,5 a 2 & 10 minutos & 1 hora & 5 a $20 \mathrm{~mL}$ \\
\hline Morfina 1\% & 0,1 & 20 a 40 minutos & 6 a 12 horas & 0,05 a $0,2 \mathrm{~mL} / \mathrm{kg}$ \\
\hline
\end{tabular}


O pênis também pode ser anestesiado pela dessensibilização do nervo dorsal do pênis (Figura 12), que se dá pela infiltração bilateral de 10 a $20 \mathrm{~mL}$ do anestésico local, aproximadamente $10 \mathrm{~cm}$ ventral ao ânus e 2,5 cm da linha média de ambos os lados, avançando a agulha cranialmente cerca de $7 \mathrm{~cm}$, até o assoalho pélvico. $\mathrm{O}$ pênis deverá apresentar relaxamento em até 20 minutos, quando do emprego da lidocaína ${ }^{43}$.

Quando é necessário realizar intervenções no úbere, pode-se empregar o bloqueio paravertebral múltiplo (lombar e sacral, bilaterais) (Figura 13A) ou a anestesia epidural cranial (Figura 13B), de forma que se consiga dessensibilizar os nervos espinhais sacrais e lombares. Para intervenções nos tetos os bloqueios infiltrativos são mais utilizados, seja circular na base do

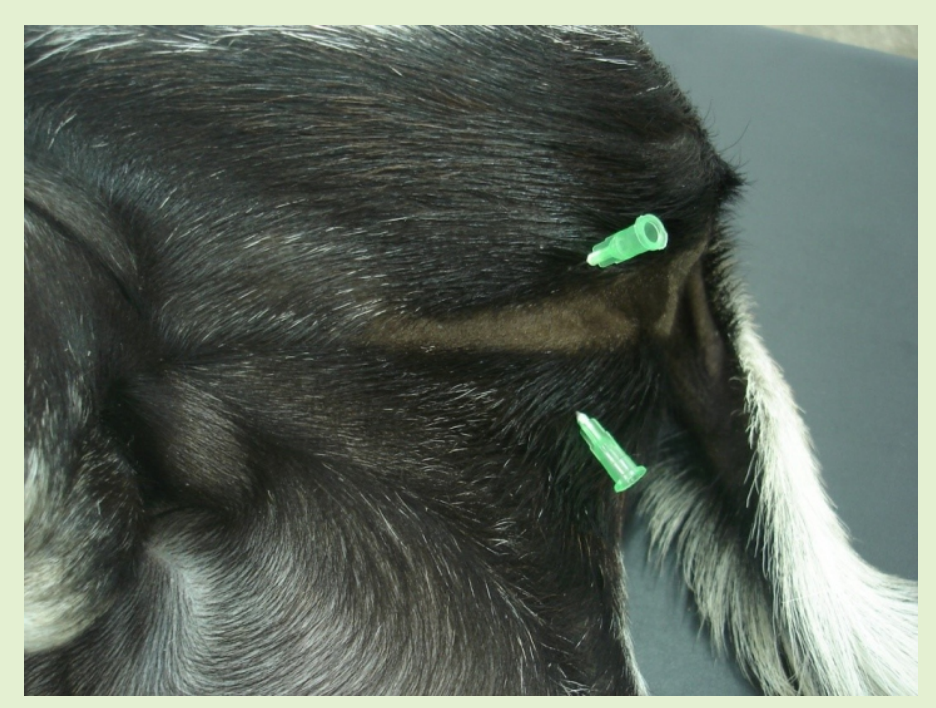

Figura 12. Posicionamento das agulhas bilateralmente em sentido dorsal do pênis e um caprino (Fonte: HVU/UFCG).
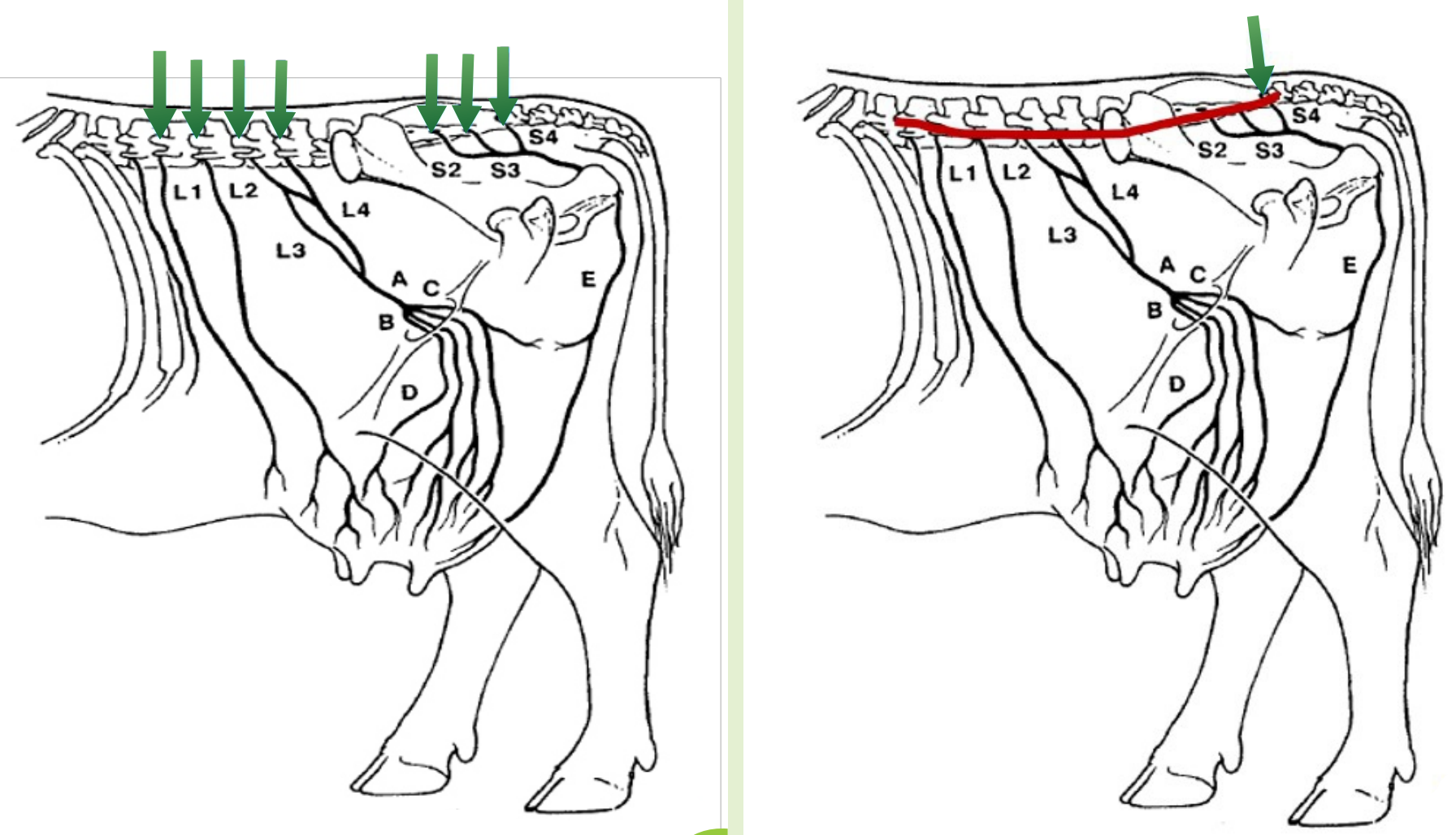

Figura 13. Ilustração dos locais de introdução das agulhas (setas verdes) para execução dos bloqueios para dessensibilizarão da glândula mamária. (A) Bloqueio paravertebral múltiplo e (B) bloqueio anestésico epidural cranial, com área de migração esperada do anestésico local, no interior do espaço epidural (linha vermelha) (Fonte: Adaptadas de Skarda e Tranquili ${ }^{44}$ ). 
teto ou em "V" invertido. Nos casos de lacerações ou fístulas na mucosa pode-se aplicar anestésico tópico dentro do canal do teto, administrando até $10 \mathrm{~mL}$, tendo-se cuidado para não permitir extravasamento do anestésico pelo óstio papilar ${ }^{43}$.

Para intervenções na região ventrolateral do tórax e abdômen, como cirurgias no úbere ou no prepúcio e cesarianas com acesso paramamário, recomenda-se também empregar o bloqueio no nervo torácico lateral (Figura 14). Este é facilmente palpável, caudal ao acrômio, entre a $5^{\mathrm{a}}$ e a $6^{\mathrm{a}}$ costela, onde deve-se administrar $5 \mathrm{~mL}$ de anestésico local, no espaço subcutâne$\mathrm{o}^{40}$.

A orquiectomia é uma das práticas cirúrgicas mais executadas em ruminantes. Para anestesia do testículo é possível empregar a técnica anestésica intrates- ticular ou a perineural intrafunicular. A intratesticular consiste na deposição do anestésico local no centro do testículo, é mais facilmente executada, porém gera mais desconforto ao animal e apresenta menor duração, quando comparada à intrafunicular. Nesta, o anestésico local é depositado no interior do funículo espermático, o mais proximal possível. O volume de anestésico empregado em ambas é de 0,05 a 0,1 mL/kg para cada testículo ou funículo espermático, até o limite máximo de $15 \mathrm{~mL} /$ testículo ou funículo. Independentemente da técnica de bloqueio testicular empregada, sempre deve-se associar a anestesia infiltrativa subcutânea em linha no local da incisão escrotal, para dessensibilização da pele, com um volume de anestésico correspondente à metade do administrado no testículo ou funículo ${ }^{43}$.

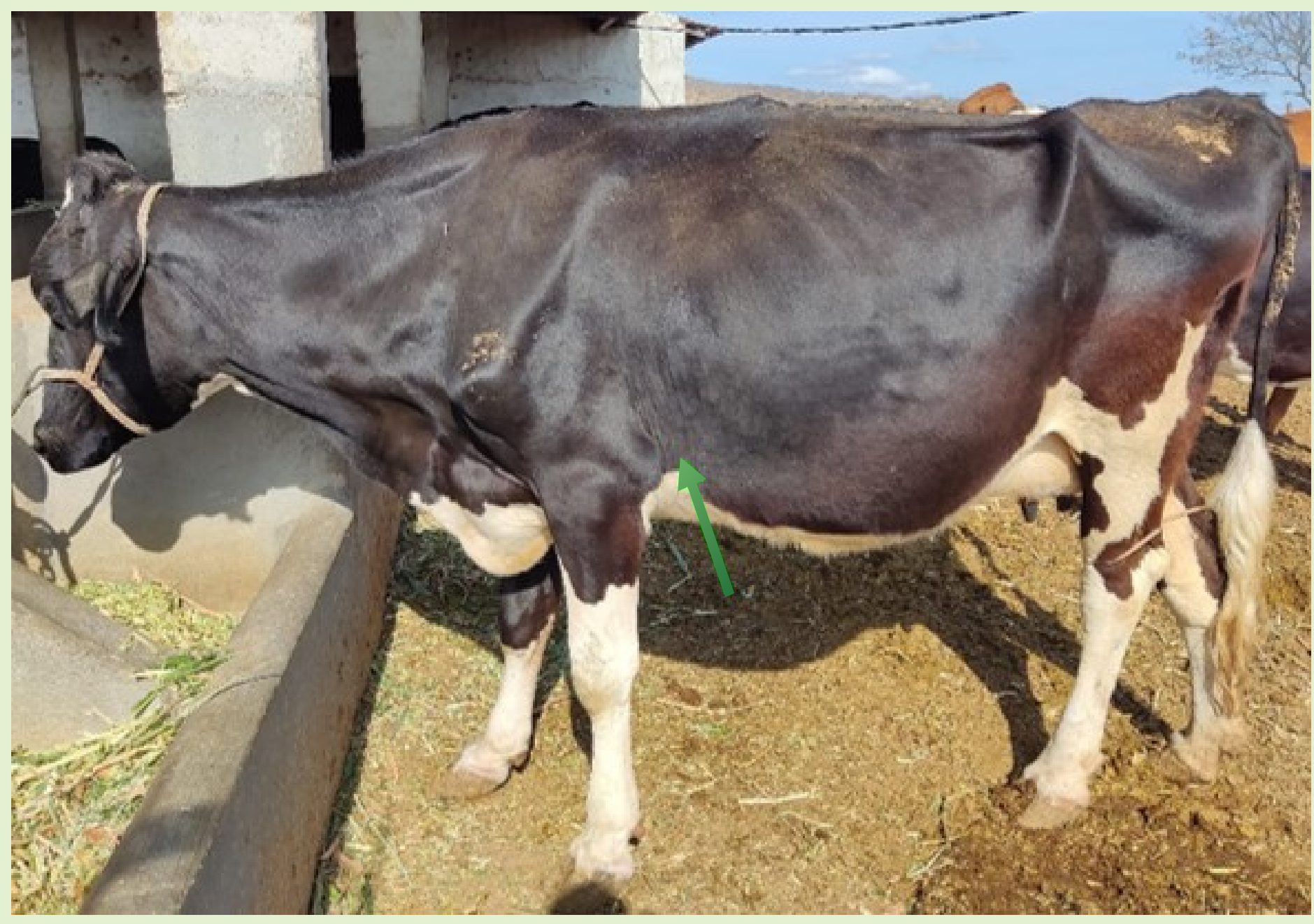

Figura 14. Local para inserção da agulha para realização do bloqueio do nervo torácico lateral (seta verde). 


\section{ANESTESIA DOS MEMBROS}

\section{- Bloqueio do plexo braquial}

O bloqueio do plexo braquial consiste na dessensibilização conjunta do $6^{\circ}, 7^{\circ}$ e $8^{\circ}$ nervos cervicais (C6, C7 e C8) e $1^{\circ}$ e $2^{\circ}$ torácicos (T1 e T2), e fornece anestesia para a região do membro torácico distal ao terço distal do úmero, incluindo este ${ }^{43}$.

Para sua execução, uma agulha de 50 a $90 \mathrm{~mm}$ (em ovinos e caprinos) e de 100 a $200 \mathrm{~mm}$ (em bovinos) de comprimento deve ser inserida medialmente à articulação escápulo-umeral e paralela à linha do dorso, até atingir a borda cranial do terço médio da $1^{\mathrm{a}} \cos ^{-}$ tela, onde se administra cerca $1 / 3$ da dose total calculada do anestésico (Figura 15). Outro 1/3 da dose deve ser aplicado $2 \mathrm{a} 4 \mathrm{~cm}$ distalmente ao primeiro ponto de administração, também imediatamente cranial à borda cranial da $1^{\mathrm{a}}$ costela. $O$ restante da dose deve ser administrado em linha de infiltração, durante a remoção da agulha ${ }^{40}$. Em cada ponto de administração deve-se descartar a punção vascular inadvertida, realizando aspiração prévia à administração do anestésico.
O volume de anestésico empregado varia de 0,1 a $0,25 \mathrm{~mL} / \mathrm{kg}^{40,51}$. A escolha do agente anestésico dependerá da duração desejada do bloqueio anestésico, sendo os mais comumente empregados a lidocaína $2 \%{ }^{40}$ e a bupivacaína $0,5 \%$, os quais, sem associação com vasoconstrictor, causam, respectivamente, 100 e 330 minutos de anestesia ${ }^{51}$. O bloqueio motor pode durar mais que o sensorial, chegando a 110 minutos para a lidocaína e 509 minutos para a bupivacaína ${ }^{51}$, o que pode impossibilitar o apoio do membro após o procedimento.

\section{- Bloqueio triplo do membro torácico (nervos mediano, ulnar, musculocutâneo)}

O bloqueio conjunto dos nervos mediano, ulnar e ramos cutâneos do musculocutâneo promove anestesia do carpo e região distal ao mesmo ${ }^{43}$.

O nervo mediano é bloqueado na face medial do membro, inserindo uma agulha a $0,5 \mathrm{a} 1 \mathrm{~cm}$ (ovinos e caprinos) e a 3 a $5 \mathrm{~cm}$ (bovinos) de profundidade, entre a borda caudal do rádio-ulna e o músculo flexor radial do carpo, no terço proximal do rádio-ulna ${ }^{43}\left(\mathrm{Fi}^{-}\right.$ gura 16A).
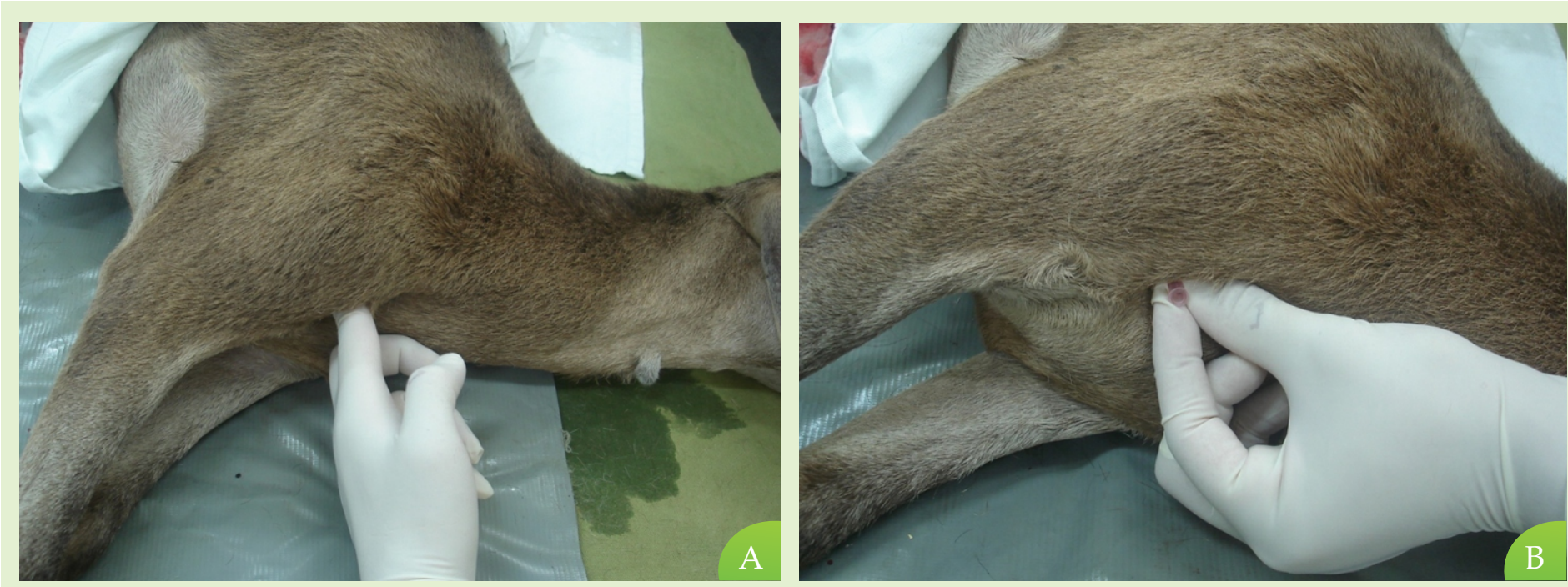

Figura 15. Posicionamento da agulha para execução do bloqueio do plexo braquial em um ovino. (A) Palpação da borda cranial da primeira costela e (B) introdução da agulha, paralela à linha do dorso (Fonte: HVU/UFCG). 

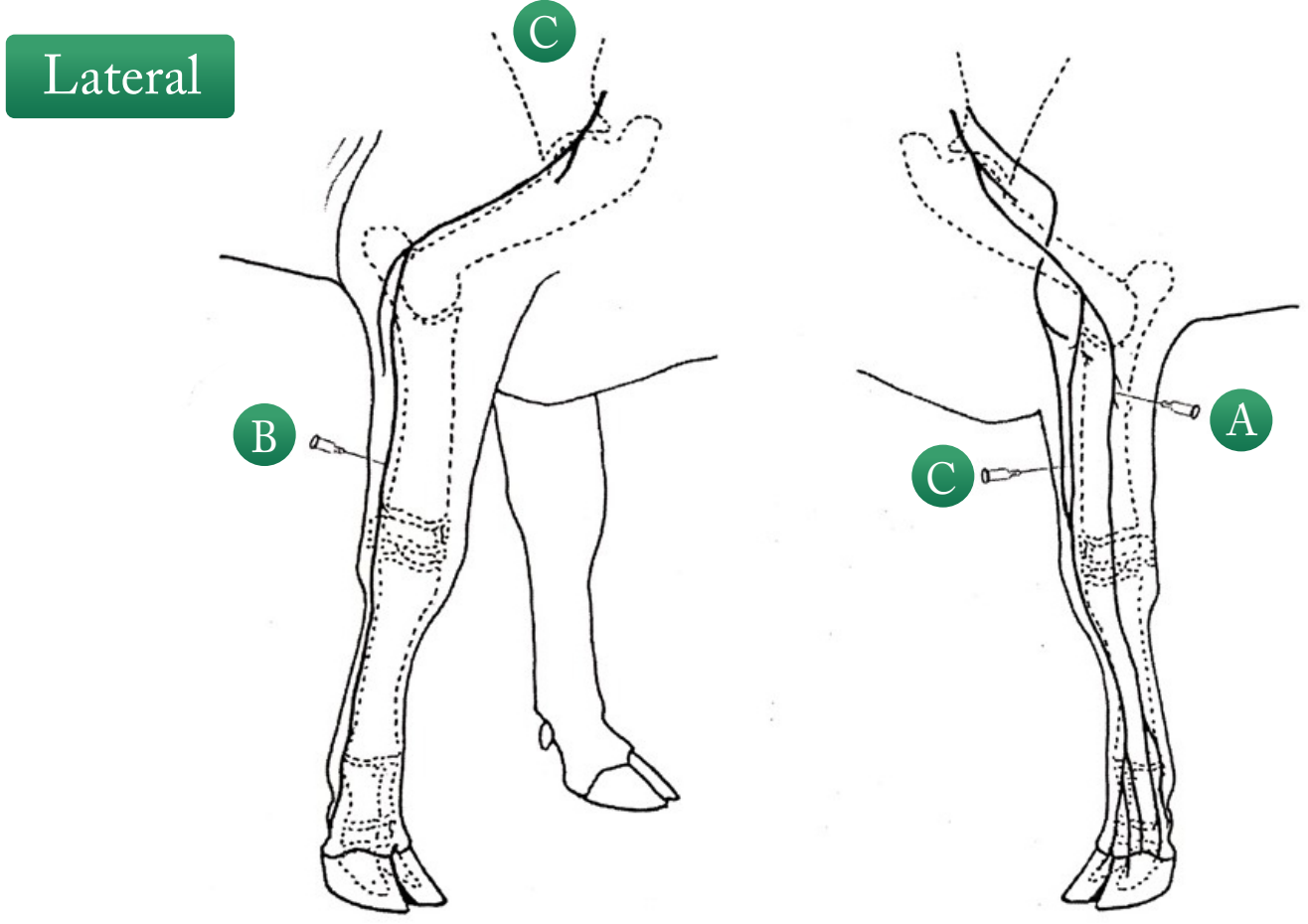

\section{Medial}

Figura 16. Locais de inserção da agulha para o bloqueio dos nervos (A) mediano,(B) ulnar e (C) musculocutâneo (Fonte: Adaptada de Santos et al. ${ }^{43}$.

Para bloqueio do nervo ulnar, insere-se uma agulha a 0,5 a $2 \mathrm{~cm}$ de profundidade (a depender do porte do animal) na face caudo-lateral do antebraço, entre os músculos ulnar lateral e flexor ulnar do carpo, de 2 (ovinos e caprinos) a $10 \mathrm{~cm}$ (bovinos) proximal ao osso acessório do carpo ${ }^{43,40}$ (Figura 16B).

Já o ramo cutâneo do nervo musculocutâneo é bloqueado no terço médio do antebraço, em sua face medial, imediatamente cranial à veia cefálica, introduzindo-se a agulha no espaço subcutâneo ${ }^{52}$ (Figura 16C).

Normalmente empregam-se entre 5 e $20 \mathrm{~mL}$ de anestésico para a anestesia do nervo mediano e de 3 a $10 \mathrm{~mL}$ para as dos nervos ulnar e musculocutâneo, com o volume variando com o porte do animal ${ }^{40,43,52}$. Da mesma forma que o citado para o bloqueio do plexo braquial, a escolha do anestésico local depende do tempo de anestesia desejado. Entretanto, devido ao bloqueio concomitante dos nervos motores do membro, recomenda-se que se evitem anestésicos locais de longa duração, de forma a permitir o apoio precoce do membro, após o procedimento ${ }^{43}$.

\section{- Bloqueio triplo do membro pélvico (nervos tibial, fibular comum e safeno)}

A anestesia do tarso e região distal ao mesmo pode ser obtida a partir do bloqueio conjunto dos nervos tibial, fibular comum e safeno ${ }^{40,43}$.

$\mathrm{O}$ acesso ao nervo tibial é feito na face medial do membro, 5 (ovinos e caprinos) a $10 \mathrm{~cm}$ (bovinos) proximal ao osso calcâneo, inserindo-se a agulha a 0,5 a $1 \mathrm{~cm}$ de profundidade, imediatamente cranial ao tendão do músculo gastrocnêmio ${ }^{43}$ (Figura 17).

Para o bloqueio do nervo fibular comum, a agulha deve ser inserida imediatamente caudal ao côn- 

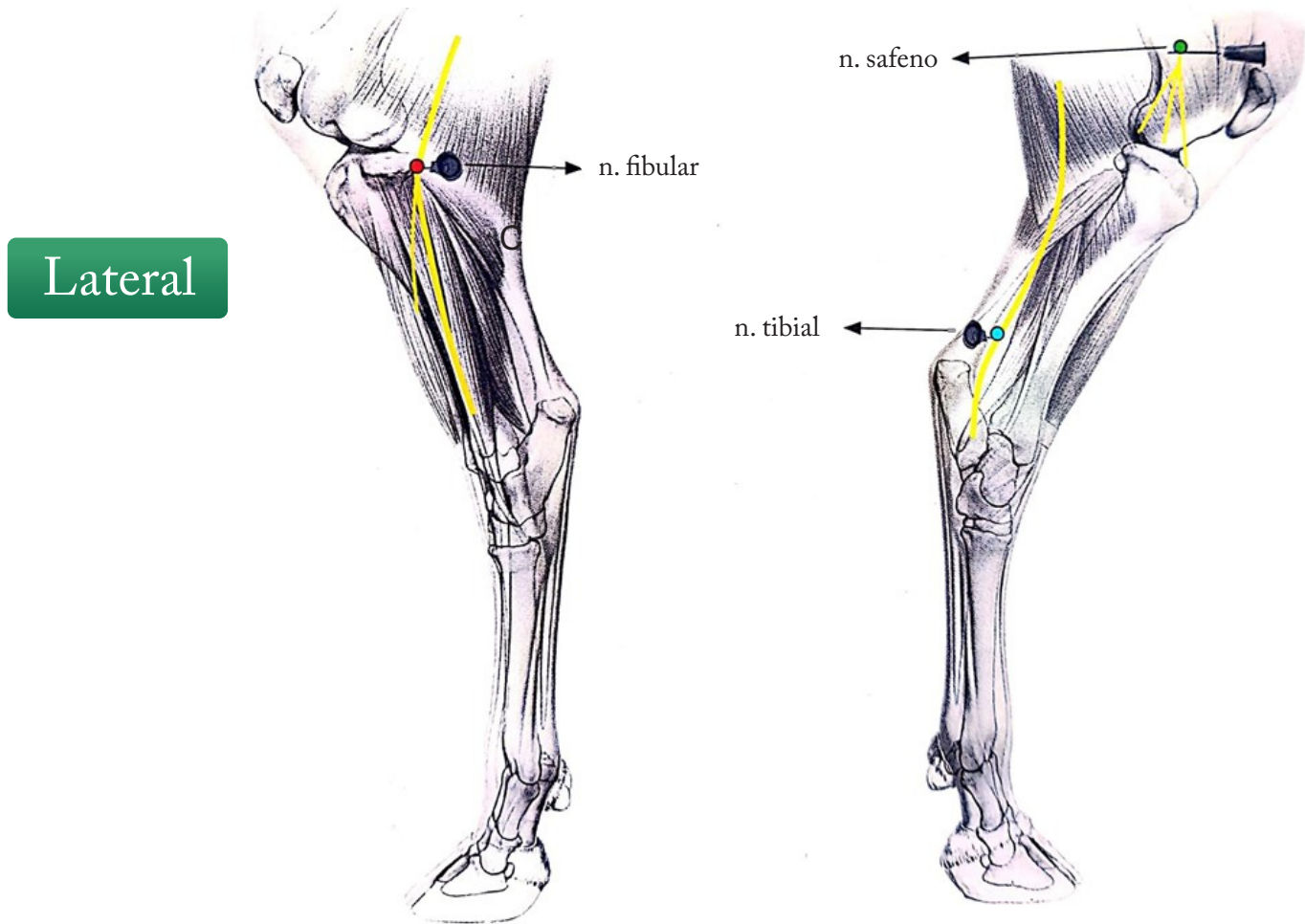

\section{Medial}

Figura 17. Locais de inserção da agulha para o bloqueio dos nervos: fibular comum, safeno e tibial (Fonte: Adaptada de Santos et al. ${ }^{43}$ ).

dilo lateral da tíbia, à profundidade de $2 \mathrm{a} 3 \mathrm{~cm}^{43}$ (Figura 17).

O nervo safeno pode ser bloqueado na face medial do membro, no terço distal do fêmur, inserindo-se a agulha imediatamente cranial à veia safena, no plano subcutâneo ${ }^{43}$ (Figura 17).

$\mathrm{O}$ volume de anestésico aplicado varia com o porte do animal, sendo geralmente de 5 (ovinos e caprinos) a $10 \mathrm{~mL}$ (bovinos) para os bloqueios dos nervos tibial e safeno, e de 5 a $10 \mathrm{~mL}$ (em ovinos e caprinos) e de 10 a $20 \mathrm{~mL}$ (em bovinos) para o bloqueio do fibular comum ${ }^{40,43}$. As observações a respeito da escolha do anestésico local feitas para o bloqueio triplo do membro torácico também se aplicam para o do membro pélvico.

\section{- Bloqueio metacarpiano}

A anestesia dos dígitos pode ser obtida com o bloqueio simultâneo dos nervos metacarpiano dorsal, palmar medial e dos ramos dorsal e lateral palmar do ulnar, os quais se encontram no espaço subcutâneo da região metacárpica distal.

Para o bloqueio do nervo metacarpiano dorsal a agulha deve ser inserida na face dorsomedial do metacarpo, medial ao tendão do músculo extensor comum dos dedos (Figura 18A). O nervo palmar medial é bloqueado inserindo-se a agulha na depressão existente entre o ligamento suspensor e o tendão flexor superficial, na face palmaromedial do metacarpo (Figura 18B). Para a anestesia do ramo dorsal do nervo ulnar deve-se inserir a agulha na face lateral do metacarpo, imediatamente dorsal ao bordo lateral do ligamento suspensor (Figura 18C). Por fim, o ramo lateral palmar do nervo ulnar é anestesiado a partir da inserção da agulha na face palmarolateral do metacarpo, na depressão existente entre o ligamento suspensor e o tendão flexor profundo (Figura 18D) ${ }^{43}$. 

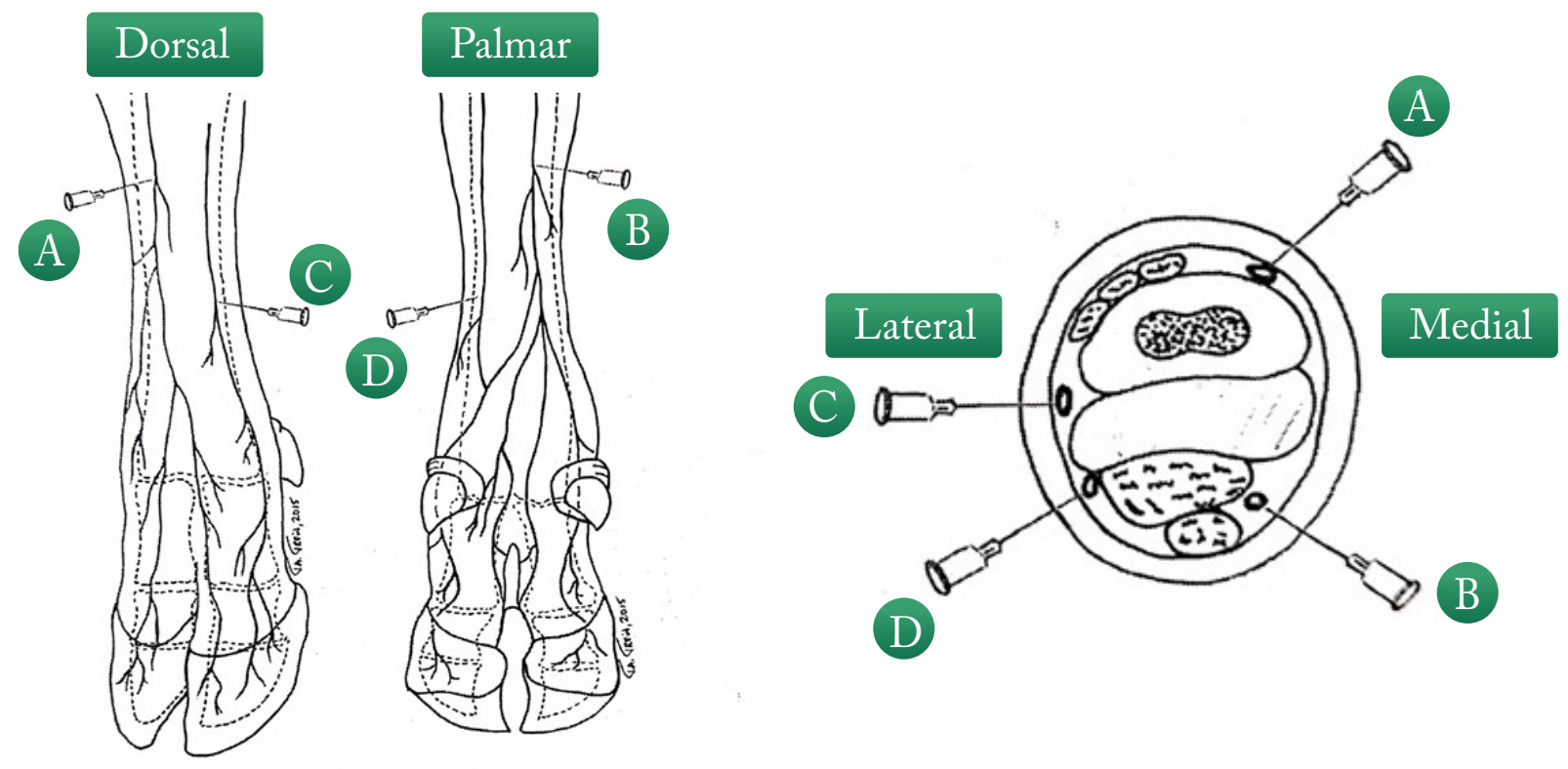

Figura 18. Locais de inserção da agulha para o bloqueio metacarpiano. (A) Nervo metacarpiano dorsal, (B) nervo palmar medial, (C) ramo dorsal do nervo ulnar e (D) ramo lateral palmar do nervo ulnar (Fonte: Adaptada de Santos et al. ${ }^{43}$ ).

Em cada ponto de inserção da agulha administram-se 3 a $5 \mathrm{~mL}$ de anestésico, empregando-se geralmente uma agulha $25 \times 7$.

\section{- Bloqueio metatarsiano}

O bloqueio metatarsiano promove anestesia do terço distal do metatarso e região distal ao mesmo. Consiste no bloqueio conjunto dos nervos metatarsiano plantar medial, metatarsiano plantar lateral e dos ramos do fibular superficial e profundo, na junção entre os terços médio e distal do metatarso ${ }^{40,43}$.

Os nervos metatarsianos plantares medial e lateral são bloqueados com a introdução de uma agulha no espaço subcutâneo, na depressão entre o ligamento suspensor e o tendão flexor profundo, medial e lateralmente, respectivamente (Figuras 19A e B). O bloqueio do ramo do nervo fibular superficial é realizado introduzindo a agulha na face dorsolateral do metatarso, entre a pele e o tendão do músculo extensor digital longo (Figura 19C), ao passo que, para o bloqueio do

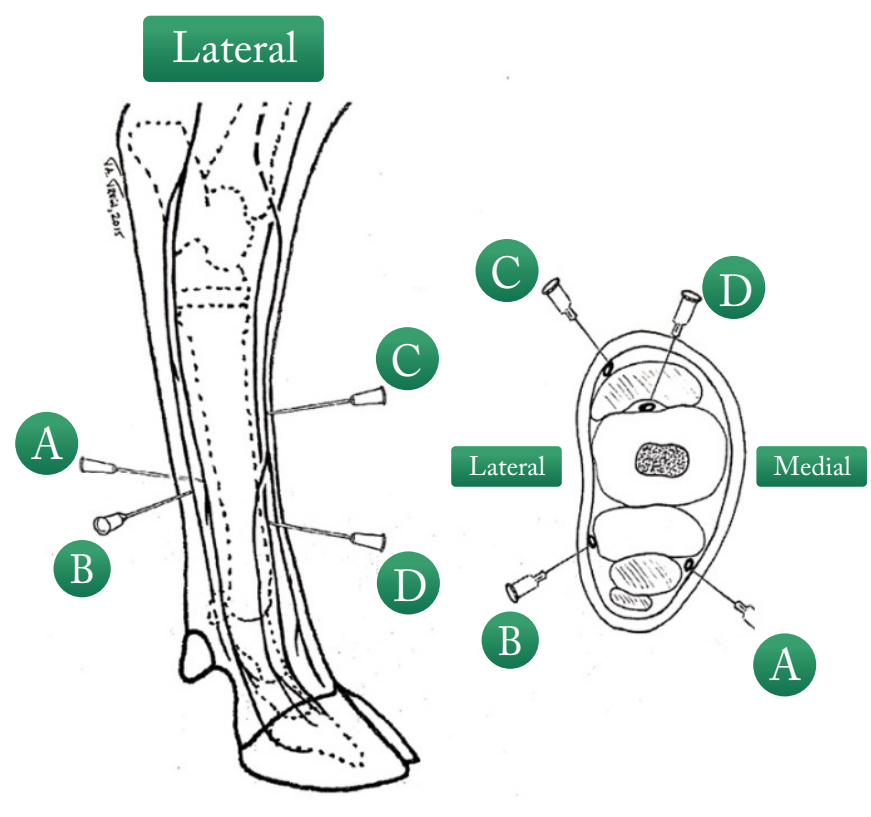

Figura 19. Locais de inserção da agulha para o bloqueio metatarsiano. (A) Nervo metatarsiano plantar medial, (B) nervo metatarsiano plantar lateral, (C) ramo do nervo fibular superficial e (D) ramo do nervo fibular profundo (Fonte: Adaptada de Santos et al. ${ }^{43}$ ). 
ramo do nervo fibular profundo, a agulha deve ser introduzida entre o tendão do músculo extensor digital longo e a face dorsal do osso metatarsiano, com acesso lateral ou medial (Figura 19D) ${ }^{43}$.

Em cada ponto de inserção da agulha administram-se 3 a $5 \mathrm{~mL}$ de anestésico, empregando-se geralmente uma agulha $25 \times 7 \mathrm{~mm}$.

\section{- Anestesia regional intravenosa (Bloqueio de Bier)}

Uma das técnicas de anestesia local mais empregadas para procedimentos que envolvam a região distal dos membros de ruminantes, a anestesia regional intravenosa consiste na deposição do anestésico local no lúmen de uma veia, após a colocação de um torniquete proximal ao local de punção. Após a administração, o anestésico se difunde para as vênulas e daí migra para o endoneuro, bloqueando a condução nervosa. É uma técnica segura, de execução relativamente simples, que necessita de uma única punção e que, pela necessidade de manutenção do torniquete "in situ", reduz o sangramento no sítio cirúrgico ${ }^{40}$.

Para sua realização, o animal deve ser contido em decúbito lateral, com o membro a ser trabalhado para cima. Deve-se realizar tricotomia e antissepsia na região a ser puncionada e em seguida aplica-se o torniquete, geralmente no terço proximal ou médio do metacarpo ou do metatarso, aplicando pressão suficiente para abolir o fluxo sanguíneo arterial. As veias mais utilizadas para a administração do anestésico são a radi- al, a metacarpiana dorsal e a metacarpiana palmar lateral, no membro torácico, e o ramo cranial da safena lateral e a digital plantar lateral, no membro pélvico ${ }^{40,43,52,53}$ (Figura 20).

Em ovinos e caprinos pode ser difícil localizar as veias da região mais distal do membro. Nestes casos, pode-se colocar o torniquete proximal ao carpo ou ao tarso, o que permitirá a punção das veias cefálica ou tarsiana recorrente, respectivamente ${ }^{52}$. Caso o torniquete precise ser aplicado proximal ao tarso, recomenda-se a colocação de rolos de tecido na depressão existente entre o tendão do gastrocnêmio e a musculatura caudal à tíbia, medial e lateralmente, para proteger o tendão e aumentar a eficiência do torniquete ${ }^{40,43}$ (Figura 20).

O anestésico local mais utilizado é a lidocaína $2 \%$ sem vasoconstrictor, em volumes de 10 a $40 \mathrm{~mL}$ para bovinos adultos e de 3 a $10 \mathrm{~mL}$ para ovinos e caprinos adultos ${ }^{40,43,52,53}$. Toda a área distal ao torniquete é anestesiada e a latência geralmente varia entre 5 e 10 minutos ${ }^{40,43,53}$, embora possa estender-se até $20 \mathrm{minu}-$ too $^{54}$. A duração da anestesia é ditada pela permanência do torniquete, o qual pode permanecer aplicado por até 2 horas, embora o ideal seja não ultrapassar 60 minutos. Em pequenos ruminantes e bezerros, não se recomenda a remoção do torniquete antes de completados 20 minutos após a administração da lidocaína, para evitar intoxicação pelo fármaco ${ }^{43}$.

Quando existe muita inflamação na região onde o anestésico será administrado, a latência pode ser estender e/ou o bloqueio pode ser falho ${ }^{43,53}$, devendo-se

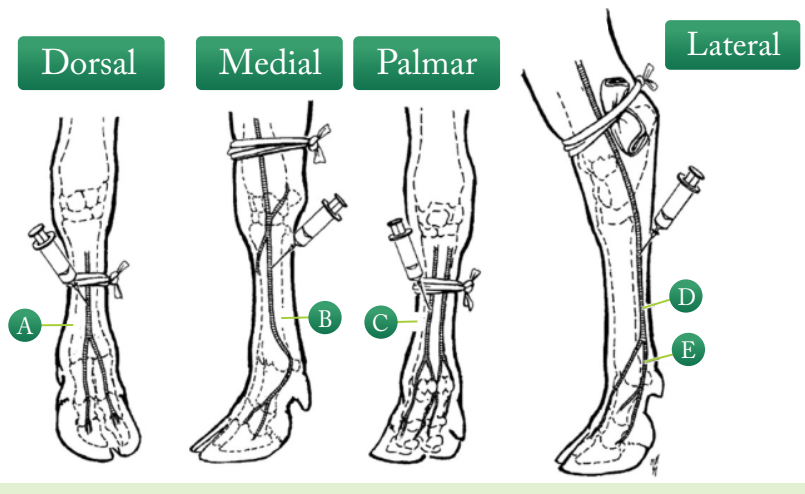

Figura 20. Veias comumente empregadas para realização da anestesia regional intravenosa. (A) Metacarpiana dorsal, (B) radial, (C) metacarpiana palmar lateral, (D) ramo cranial da safena lateral e (E) digital plantar lateral (Fonte: Adaptada de Valverde e Sinclair ${ }^{40}$. 
aumentar um pouco a quantidade empregada de anestésico $^{53}$. Como limitações adicionais da técnica, citamse a necessidade de decúbito para execução, a limitação da anestesia ao tempo de permanência do torniquete, o risco de formação de hematoma no local de punção e o desconforto causado pelo torniquete, além da possibilidade de lesão aos tecidos onde o mesmo foi aplicado (incluindo nervos superficiais) $^{40}$.

\section{- Anestesia infiltrativa subcutânea circular (Bloqueio em anel)}

Esta técnica é uma opção aos bloqueios perineurais e à anestesia regional intravenosa (Bier), especialmente quando existe muito edema e/ou inflamação na região distal ao terço médio do metacarpo/metatarso.

Para sua execução, deposita-se o anestésico de forma subcutânea ao redor do terço proximal do metacarpo/metatarso, visando formar uma linha de anestesia em todo o perímetro do membro. Geralmente utiliza-se uma agulha $25 \times 7 \mathrm{~mm}$ e o volume de anestésico administrado varia de 3 a $5 \mathrm{~mL}$ em ovinos e caprinos e de 10 a $15 \mathrm{~mL}$ em bovinos adultos ${ }^{52}$. Recomenda-se evitar o emprego de anestésico local com vasoconstritor, para evitar a descamação de epiderme que pode ocorrer, em decorrência da constrição das arteríolas dérmicas.

\section{ANESTESIA INTRAVENOSA}

A administração de anestésicos por via IV, na maioria das vezes, é utilizada para gerar um estado de inconsciência e/ou de imobilidade que seja adequado para a realização da intubação orotraqueal e subsequente manutenção da anestesia com um agente anestésico inalatório. A anestesia intravenosa em ruminantes é uma técnica bastante difundida (embora menos empregada do que em animais de pequeno porte e em equinos) que se caracteriza pela indução e manutenção da anestesia sendo realizadas exclusivamente por via intravenosa, com o intuito de fornecer aos pacientes: analgesia, relaxamento muscular, proteção neurovegetativa e hipnose/imobilidade.

O uso dessa técnica tem se popularizado, uma vez que, em boa parte dos casos, não necessita de equipamentos onerosos e que pode ser realizada apenas com seringa e acesso venoso, o que facilita seu emprego em procedimentos realizados sob condições de campo. A evolução da técnica e a constante busca por fármacos com perfis farmacocinéticos adequados tem feito com que equipamentos que facilitam o ajuste das doses e prevejam a concentração plasmática das drogas tenham sido introduzidos na rotina clínico-cirúrgica.

Ainda existe uma longa e incansável busca por um anestésico que reúna todas as características necessárias para que se tenha uma anestesia dita adequada: que seja hidrossolúvel, tenha ampla margem de segurança e baixo volume a ser infundido para realização da anestesia, não apresente efeitos cumulativos exacerbados e que seus metabólitos sejam prontamente eliminados, possua farmacocinética e farmacodinâmica bem caracterizadas, período de carência bem estabelecido e, por fim, não produza alterações imprevisíveis e potencialmente fatais ${ }^{55}$.

\section{RECOMENDAÇÕES PRÉ-ANESTÉSICAS}

A anestesia geral em ruminantes é um procedimento delicado que demanda decúbito prolongado e portando exige cuidados específicos. Devido à fisiologia do seu trato gastrointestinal é iminente o risco de regurgitação e aspiração do conteúdo ruminal ou da própria saliva. $\mathrm{O}$ posicionamento do paciente é um aspecto relevante para minimizar as complicações durante a anestesia geral. Tanto o decúbito dorsal quanto o lateral impedem a eructação, facilitam a regurgitação do conteúdo ruminal, interferem na ventilação por compressão das vísceras abdominais no diafragma e desequilibram a relação ventilação/perfusão. $O$ decúbi- 

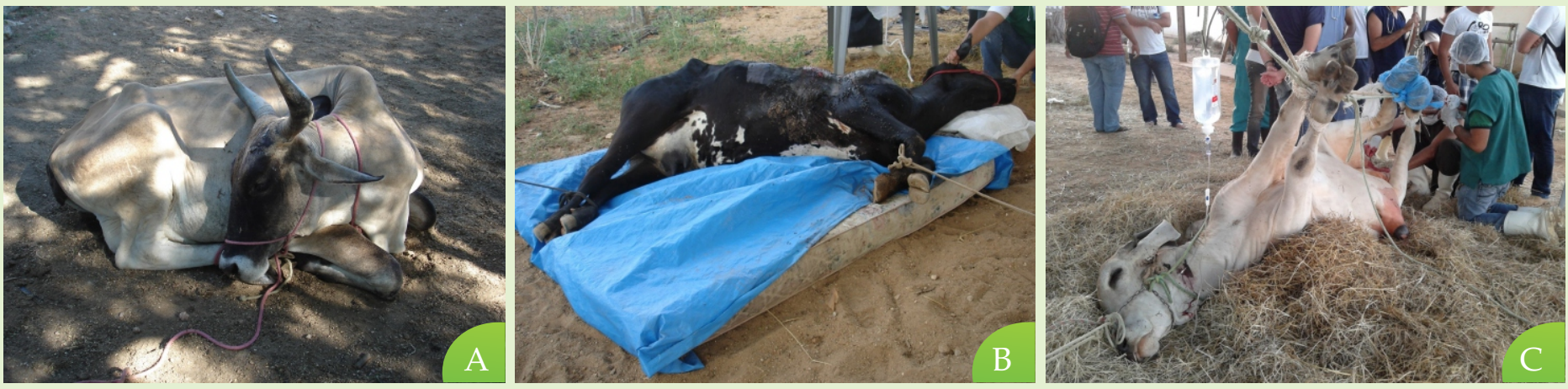

Figura 21. Métodos de contenção de bovinos em decúbito após administração de anestésico. (A) Decúbito esterno-abdominal em contato direto com solo. (B) Decúbito lateral e (C) dorsal, sobre substrato macio (colchão e feno respectivamente) (Fonte: HVU/UFCG).

to, seja dorsal ou lateral, por si só reduz significantemente $\mathrm{PaO}_{2}$ e o $\mathrm{pH}$ e, quando associado à anestesia, o impacto ao sistema cardiorrespiratório é ainda mais severo justificando, pois, a suplementação com oxigênio $^{56}$. O decúbito lateral esquerdo também comprime o rúmen, o que impede sua expansão. Dessa forma hipoventilação, hipoxemia e timpanismo apresentam grandes riscos para ruminantes anestesiados. Assim, a posição esterno-abdominal (Figura 21A), quando possível ser adotada, é considerada a mais adequada para minimizar as complicações trans-anestésicas ${ }^{20,56,57}$. Quando o decúbito é essencial ao procedimento, deve-se acomodar o animal sobre um substrato macio e posicionar os membros do modo mais natural possível, evitando hiperflexões ou hiperextensões de articulações (Figuras 21B e C).

Outro cuidado pré-anestésico que deve ser considerado é o jejum prévio, pois auxiliará a reduzir a taxa de fermentação do rúmen e em certo grau o timpanismo. A recomendação do tempo de jejum sólido e líquido varia entre autores. $\mathrm{O}$ jejum sólido oscila entre 12 e 24 horas para pequenos ruminantes adultos e 24 e 48 horas para bovinos. O jejum alimentar muito prolongado, contudo, deve ser evitado em ovelhas e cabras prenhes e muito pesadas, pois pode predispor à acidose metabólica.

A restrição de líquido pode variar entre 2 e 6 horas em pequenos ruminantes ou até mesmo a sua não realização, dependendo da condição do paciente; e de 8 a 12 horas em outros ruminantes ${ }^{20,56,57}$. Ainda que seja realizado o jejum corretamente, a forma mais segura de evitar a aspiração de conteúdo ruminal e obstrução da via aérea é a intubação traqueal, usando sonda orotraqueal cujo balonete se mantenha inflado. Caso não seja possível a intubação, a cabeça deve ser posicionada de modo que os lábios permaneçam em um nível abaixo da laringe, a fim de que a saliva e o conteúdo ruminal porventura regurgitado sejam drenados para fora da cavidade oral ${ }^{20}$ (Figura 22).

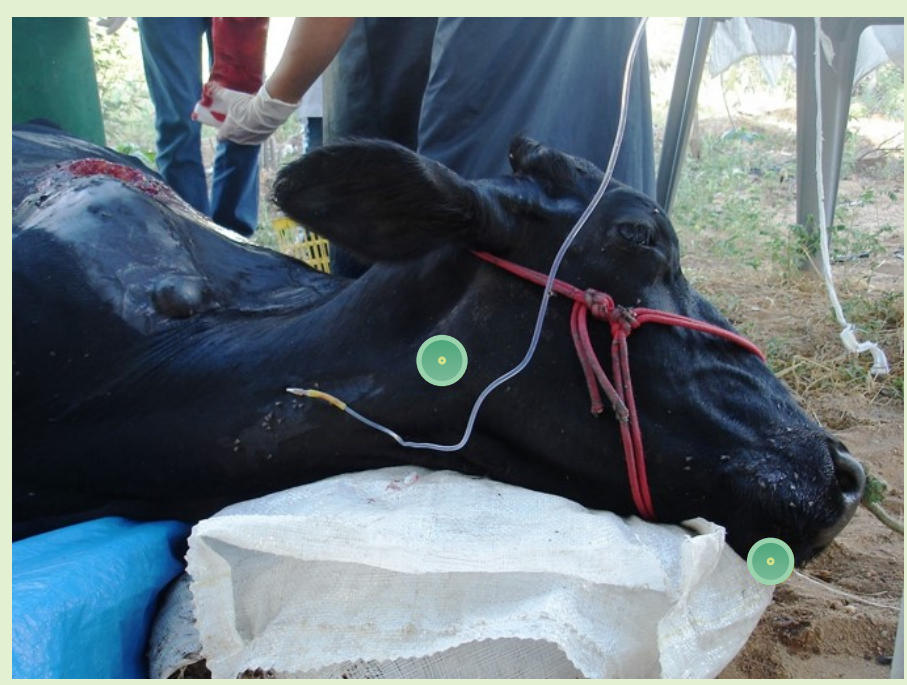

Figura 22. Bovino contido em decúbito lateral, evidenciando o posicionamento correto da cabeça, de modo que a laringe fique em nível mais alto que o lábio (círculo verde) (Fonte: HVU/UFCG). 
A avaliação física não deve ser negligenciada no período pré-anestésico e,juntamente com exames complementares, irá auxiliar a determinação do risco anestésico, planejamento de protocolos e de condutas emergenciais. Recomenda-se manter acesso venoso antes de iniciar qualquer procedimento, pois permite a administração de fármacos e fluidos e é essencial em situações de emergência ${ }^{20}$.

\section{INDUÇÃO E MANUTENÇÃO DA ANESTESIA INTRAVENOSA}

Diferentemente de outras espécies, os ruminantes não precisam efetivamente de sedação para que se tenha uma indução adequada. Em determinadas ocasiões, a contenção física não traumática pode ser realizada no lugar da administração de sedativos. Os ruminantes, quando comparados a outras espécies, raramente apresentam delírio na fase de recuperação anestésica. Isso é muito importante, uma vez que não é necessário a sedação desses pacientes no pósoperatório imediato. Entretanto, a sedação em alguns animais irascíveis faz-se necessária, uma vez que torna a indução anestésica mais segura e evita acidentes. Vale salientar que a sedação pré-indução prolonga o período de recuperação anestésica, diminui o requerimento de anestésico geral e aumenta a probabilidade de regurgitação e aspiração de conteúdo gástrico, caso esse animal não esteja intubado preventivamente ${ }^{7,55,58}$.

A indução e manutenção da anestesia intravenosa pode ser realizada com diversos fármacos e associações farmacológicas. Os mais comumente utilizados incluem a cetamina e escetamina, anteriormente denominada de dextrocetamina, éter gliceril guaiacol (EGG), propofol, associação de tiletaminazolazepam, tiobarbitúricos e alfaxolona ${ }^{55}$.

Os anestésicos dissociativos, derivados da fenciclidina, produzem um estado denominado "anestesia dissociativa”, na qual há uma dissociação dos sistemas talamocortical e límbico, bem como promovem anal- gesia, tanto no período peri quanto no pós-operatório, amnésia e paralisia dos movimentos, causando alterações no estado de consciência ${ }^{55,59,60}$.

Os fármacos dissociativos mais comumente utilizados na medicina veterinária são o cloridrato de cetamina e o cloridrato de tiletamina. Mais recentemente, foi disponibilizada a cetamina $\mathrm{S}+$, também conhecida como dextrocetamina e escetamina, obtida a partir da purificação da cetamina racêmica. Uma das suas principais vantagens dos agentes dissociativos é o rápido início de ação quando administrados por via IV, atingindo concentrações plasmáticas máximas em 1 minuto ${ }^{55}$.

Uma característica desse tipo de anestesia é que os animais atingem um estado semelhante à catalepsia, com rigidez muscular, tremores e movimentos involuntários, embora menos frequentes em ruminantes, no qual o paciente parece estar acordado, porém, sem resposta aos estímulos externos. Diferente de outros anestésicos injetáveis, os quais diminuem o fluxo sanguíneo cerebral, a cetamina tende a causar vasodilatação cerebral, acrescida do aumento da pressão arterial, resultando em acréscimo na pressão intracraniana. Embora presente, o reflexo de deglutição não impossibilita a intubação de ruminantes quando anestesiados com cetamina ${ }^{55,61}$.

Mais comumente, recomenda-se a associação de fármacos que causem miorrelaxamento, tais como agonistas alfa-2 adrenérgicos e benzodiazepínicos, à cetamina e à escetamina. A administração de xilazina na pré-medicação facilita o manejo e retira a necessidade de se repetir esse fármaco por via IV. Em caprinos e ovinos, a administração de 0,1 a $0,2 \mathrm{mg} / \mathrm{kg}$ de xilazina por via IM, seguida de 1 a $2 \mathrm{mg} / \mathrm{kg}$ de cetamina, pela via $\mathrm{IV}$, fornece uma anestesia adequada por aproximadamente 45 minutos ${ }^{7}$. Devido à característica de maior duração da sedação da xilazina, a anestesia pode ser prolongada pela administração de cetamina, na dose de $1 \mathrm{mg} / \mathrm{kg}$, IV, após os 45 minutos $^{7}$. Nos casos em que se tem o acesso venoso facilitado, o uso da xilazina na dose 
de 0,03 a $0,05 \mathrm{mg} / \mathrm{kg}, \mathrm{IV}$, seguido de bolus de cetamina na dose de 3 a $5 \mathrm{mg} / \mathrm{kg}$, IV, fornece uma anestesia de 15 a 20 minutos de duração ${ }^{7}$. Em bovinos, o uso da associação xilazina-cetamina tem sido estudada. $\mathrm{O}$ bolus de xilazina, na dose de 0,1 a 0,2 $\mathrm{mg} / \mathrm{kg}, \mathrm{IV}$, seguido da administração de cetamina, na dose de $2 \mathrm{mg} / \mathrm{kg}$, IV, teve duração de 30 minutos, podendo ser prolongada por 15 minutos quando da administração de bolus adicional de cetamina, na dose 0,75 a 1,25 mg/ $/ \mathrm{kg} \mathrm{IV}{ }^{55,62}$.

Em ovinos, a administração de xilazina, na dose de $0,1 \mathrm{mg} / \mathrm{kg}$, IV, seguido de bolus de cetamina $(7,5$ $\mathrm{mg} / \mathrm{kg}, \mathrm{IV})$, produziu uma anestesia de 25 minutos de duração. Vale ressaltar que a administração dessa associação resultou em diminuição significativa do débito cardíaco, pressão arterial e da resistência vascular periférica ${ }^{63}$.

Os benzodiazepínicos são comumente associados à cetamina para contenções de ruminantes. Esses fármacos possuem características hipnótica, ansiolítica, anticonvulsivante e miorrelaxante. Seus efeitos cardiocirculatórios são mínimos e possuem ampla margem de segurança. Quando associado à cetamina (4,5 $\mathrm{mg} / \mathrm{kg}, \mathrm{IV}$ ) o diazepam, na dose de $0,1 \mathrm{mg} / \mathrm{kg}$, proporciona relaxamento muscular adequado, o que permite, na maioria das situações, a intubação orotraqueal, mesmo com o reflexo lanringotraqueal presente, fornecendo uma contenção de aproximadamente 10 a 15 minutos. Em ovinos, mesmo com doses mais elevadas de diazepam-cetamina, a duração da anestesia parece ser a mesma ${ }^{7,63,64}$.

Em caprinos, foi avaliado o uso da dextrocetamina (escetamina) para indução da anestesia. Pacientes anestesiados com $3 \mathrm{mg} / \mathrm{kg}$ de dextrocetamina e prémedicados com $0,05 \mathrm{mg} / \mathrm{kg}$ de xilazina, tiveram redução da frequência cardíaca em 33,6\%, entretanto, os valores de pressão arterial mantiveram-se dentro dos limites fisiológicos para a espécie. Após a administração da dextrocetamina pode ocorrer opistótono e tremores musculares de curta duração, com relaxamento muscular adequado posteriormente. Quando compa- rada com a cetamina racêmica, em mesma dose, a dextrocetamina promove anestesia e recuperação anestésica semelhantes, inclusive com a mesma repercussão hemodinâmica e efeitos indesejáveis ${ }^{65}$.

A associação tiletamina-zolazepam tem sido utilizada com frequência em ruminantes. Assim como a cetamina, essa associação promove aumento da pressão arterial, da resistência vascular periférica, da frequência cardíaca e do débito cardíaco. É composta por partes iguais de um agente dissociativo, a tiletamina, e de um benzodiazepínico, o zolazepam. $\mathrm{O}$ agente dissociativo promove espasticidade muscular, sendo assim, o zolazepam contrabalanceia esse efeito. $\mathrm{O}$ reflexo de deglutição por vezes está presente, dificultando a intubação orotraqueal quando da utilização desta associação. A depuração dos dois fármacos ocorre de forma diferente, isso pode refletir na qualidade da recuperação anestésica ${ }^{6}$.

A administração da tiletamina-zolazepam em bezerros, na dose de $4 \mathrm{mg} / \mathrm{kg}$, pela via IV, proporcionou anestesia com duração de 60 minutos, com mínimos efeitos cardiovasculares ${ }^{66}$. Após a administração dos fármacos, a indução é rápida e suave, sendo a recuperação lenta e gradativa. Por vezes, ocorre redução da frequência respiratória e padrão respiratório apnêustico. Pode ocorrer a necessidade de intubação orotraqueal e fornecimento de $\mathrm{O}_{2}$ nos casos de hipoventilação e hipoxemia graves. Além disso, pode haver necessidade de ventilação controlada ${ }^{67}$. Outras medicações podem ser associadas para promover maior tempo de anestesia.

Ovinos submetidos à anestesia com tiletaminazolazepam, na dose de $12 \mathrm{mg} / \mathrm{kg}$, IV, permaneceram anestesiados por aproximadamente 2,5 horas, e o tempo de decúbito foi de 3,2 horas ${ }^{6,68}$. Estudos têm demonstrado que doses altas estão relacionadas à maior depressão respiratória e ao aumento na necessidade de intubação traqueal de emergência. Uma alternativa mais efetiva seria a redução da dose da associação, administrando outros fármacos adjuvantes. A administração de tiletamina-zolazepam, na dose de 2 a $4 \mathrm{mg} / \mathrm{kg}$, IV, 
seguida de bolus de butorfanol, na dose de $0,05 \mathrm{mg} / \mathrm{kg}$, IV, promoveu anestesia de 25 a 50 minutos de duração com mínimos efeitos cardiovasculares e menor tempo de decúbito ${ }^{69}$.

O EGG é um relaxante muscular de ação central, com efeito nos neurônios internuncias da medula espinhal. Tem sido utilizado em ruminantes para induzir o decúbito, muito embora seja utilizado mais frequentemente associado a outros fármacos que forneçam analgesia e maior potencial hipnótico, a fim de reduzir as doses gerais dos sedativos e anestésicos, minimizando os efeitos cardiorrespiratórios ${ }^{6,70}$. Tipicamente são utilizadas soluções de EGG em concentrações de $5 \%$ a $10 \%$, diluído em cloreto de sódio $0,9 \%$ ou solução de dextrose 5\%, sendo esta última a mais indicada. A solução deve ser infundida rapidamente, seja por gravidade ou com auxílio de bolsa pressórica. Vale ressaltar que soluções mais concentradas possuem uma maior probabilidade de causar hemólise, formação de trombos intravasculares e flebite. A injeção perivascular está associada à necrose tecidual, ressaltando a importância da infusão da solução via cateter venoso de grande calibre ${ }^{6,70,71}$. O EGG possui ampla margem de segurança e os efeitos cardiovasculares são mínimos, quando utilizado em doses terapêuticas. A frequência cardíaca, débito cardíaco e pressão venosa central mantêm-se inalteradas quando do uso deste fármaco ${ }^{71}$.

Vários fármacos são utilizados em associação ao EGG para anestesia em ruminantes, sendo que o protocolo mais conhecido é a associação xilazinacetamina-EGG. Dez minutos após a medicação préanestésica com xilazina $(0,05 \mathrm{mg} / \mathrm{kg}, \mathrm{IV})$, utiliza-se a cetamina para indução, na dose de 1 a $2 \mathrm{mg} / \mathrm{kg}$, IV, e a manutenção é realizada com uma solução contendo xilazina, cetamina e EGG, nas concentrações de 0,1 $\mathrm{mg} / \mathrm{mL}$, 1 a $2 \mathrm{mg} / \mathrm{mL}$ e $50 \mathrm{mg} / \mathrm{mL}$, respectivamente. A taxa de infusão para indução (caso prefira-se induzir com a própria solução anestésica, ao invés de usar apenas a cetamina) varia de 0,5 a $1 \mathrm{~mL} / \mathrm{kg}$, e para manutenção de 1 a $2 \mathrm{~mL} / \mathrm{kg} / \mathrm{h}^{71}$.
Pode ocorrer acentuada redução da frequência cardíaca, atribuída principalmente aos efeitos simpatolíticos da xilazina. Os valores de pressão venosa de dióxido de carbono $\left(\mathrm{P}_{\mathrm{V}} \mathrm{CO}_{2}\right)$ podem aumentar, bem como pode haver redução dos valores de pressão arterial de oxigênio $\left(\mathrm{P}_{\mathrm{A}} \mathrm{O}_{2}\right)$ e pressão venosa de oxigênio $\left(\mathrm{P}_{\mathrm{V}} \mathrm{O}_{2}\right)$, porém podem ser compensados pela elevação da frequência respiratória ${ }^{70}$. $\mathrm{O}$ fornecimento de $\mathrm{O}_{2}$ parece não prevenir a hipoxemia em bovinos submetidos a esse tipo de anestesia ${ }^{72}$. O tempo de recuperação da anestesia tende a ser elevado quando comparado a outras modalidades. Em bezerros submetidos à herniorrafia umbilical, o tempo médio de recuperação foi de 152 minutos. Segundo os autores, esse efeito poderia ser minimizado ajustando as doses de xilazina e EGG sendo, portanto, necessários outros estudos para avaliarem essa proposta ${ }^{70}$.

Embora a utilização da anestesia barbitúrica seja menos frequente atualmente, os barbitúricos foram muito utilizados para indução e manutenção da anestesia em ruminantes. O tiopental foi muito utilizado para indução da anestesia em ovinos e caprinos, por proporcionar um rápido início de ação, podendo ser titulado até o efeito desejado. Em animais que não foram pré-medicados, a dose de indução pode variar de 7 a $20 \mathrm{mg} / \mathrm{kg} \mathrm{IV}^{73}$. Uma forma de se obter uma indução segura, com mínimos efeitos cardiovasculares, consiste na administração de metade da dose de forma rápida e bolus subsequentes mais lentamente, a fim de se obter o relaxamento muscular adequado para intubação orotraqueal $^{74}$. A anestesia é de curta duração, de 5 a 10 minutos, e a recuperação é suave e tranquila ${ }^{73}$.

Os efeitos cardiovasculares do tiopental são mínimos. Alguns animais podem apresentar taquicardia moderada com aumento subsequente da pressão arterial e depressão respiratória moderada de curta duração ${ }^{19}$. Vale ressaltar que o tiopental não possui efeito analgésico, sendo necessário administração de outros fármacos para esse fim ${ }^{6}$. Os barbitúricos são biotransformados mais rapidamente em caprinos e 
ovinos, dessa forma, essas espécies necessitam de doses mais elevadas para indução e manutenção da anestesia. É importante lembrar do potencial acumulativo que esses fármacos possuem, portanto, reaplicações podem ocasionar retardo na recuperação da anestesia ${ }^{19}$.

O propofol é um agente de indução e manutenção da anestesia, fornecendo hipnose, relaxamento muscular e baixo impacto sobre as variáveis hemodinâmicas. Uma das principais vantagens é o despertar rápido e tranquilo, tornando-se muitas vezes o agente de escolha para manutenção da anestesia em medicina veterinária ${ }^{55}$. Esse fármaco vem sendo usado com frequência em caprinos, ovinos e bovinos, sendo suas características semelhantes àquelas descritas para cães e gatos. A dose utilizada para indução da anestesia varia de 4 a $6 \mathrm{mg} / \mathrm{kg}$, via IV, sendo muitas vezes necessárias doses complementares para realização da intubação orotraqueal ${ }^{75}$. A associação de propofol (3 $\mathrm{mg} / \mathrm{kg}, \mathrm{IV})$ e cetamina $(1 \mathrm{mg} / \mathrm{kg}, \mathrm{IV})$ tem sido utilizada para indução da anestesia, com posterior infusão contínua de propofol, com taxas de 0,2 a 0,3 $\mathrm{mg} / \mathrm{kg} / \mathrm{minuto}$, e de cetamina, $0,1 \mathrm{a} 0,2 \mathrm{mg} / \mathrm{kg} / \mathrm{minuto}$, ambos via $\mathrm{IV}^{76}$.

A alfaxolona é um fármaco que foi liberado recentemente para uso em animais, e que ainda não é comercializado no Brasil. Poucos trabalhos avaliaram o seu uso em animais de produção. A administração em ovinos, na dose de $2 \mathrm{mg} / \mathrm{kg}$, via IV, foi suficiente para produzir breves períodos de anestesia, com menores impactos sobre as variáveis hemodinâmicas do que o tiopental e o propofol. Em ovinos não sedados, a administração de $2 \mu \mathrm{g} / \mathrm{kg}$ de medetomidina associada à alfaxolona ( $2 \mathrm{mg} / \mathrm{kg}$ ), ambos pela via IV, permitiu a intubação orotraqueal, forneceu um bom relaxamento muscular e um breve período de recuperação ${ }^{77}$.

$\mathrm{Na}$ Tabela 3 estão sumarizadas as informações acerca de alguns protocolos de anestesia intravenosa utilizados em caprinos, ovinos e bovinos.

\section{ANESTESIA INALATÓRIA}

A escolha do protocolo anestésico para ruminantes, como em qualquer paciente, deve ser definida de acordo com o tipo e duração do procedimento a ser realizado, o tipo de paciente submetido ao procedimento, a disponibilidade de equipamentos e fármacos e o conhecimento técnico do anestesista para a realização do protocolo definido ${ }^{78}$. Quando se trata de pacientes debilitados, neonatos e pediátricos, idosos, cirurgias prolongadas e complexas, deve-se optar pela inclusão $\mathrm{da}$ anestesia inalatória no protocolo anestésico ${ }^{20}$. Contudo, em situação de campo é mais frequente a realização de procedimentos em ruminantes sob anestesia local, associada ou não à sedação ou tranquilização ${ }^{79}$. No entanto, a anestesia inalatória nesses pacientes pode trazer muitos benefícios, como proteção da via aérea, evitando-se a aspiração de conteúdo salivar ou ruminal devido à facilidade de regurgitação nesses animais; controle da ventilação, minimizando o desequilíbrio da relação ventilação/perfusão; facilidade de controle dos planos anestésicos; e ausência de acúmulo de fármacos anestésicos $^{3,78}$ (Figura 23).

Além da necessidade do aparelho de anestesia inalatória, a oferta do anestésico inalatório demanda uma via respiratória para seu fornecimento, que pode ser por meio de máscara ou tubo orotraqueal, sendo essa última a opção mais segura para a manutenção do ruminante em decúbito por um período prolongado. A intubação em ruminantes requer certa habilidade do anestesista, uma vez que esses animais possuem tórus lingual, cavidade oral estreita e longa, além do ângulo da laringe que dificulta a visualização da glote. A intubação pode ser realizada de duas maneiras: por meio da palpação (Figura 27) ou da visualização da laringe (Figura 28).

Em bovinos adultos indica-se o auxílio das mãos para palpar as aritenóides e guiar a sonda até a glote, enquanto que em pequenos ruminantes e bezerros é possível realizar a intubação posicionando o ani- 
Tabela 3.Protocolos de anestesia intravenosa empregados em ruminantes.

\begin{tabular}{|c|c|c|c|c|}
\hline Fármacos & Dose (mg/kg) & Espécies & $\begin{array}{l}\text { Duração da } \\
\text { anestesia }\end{array}$ & Prolongamento da anestesia \\
\hline & $\begin{array}{l}0,1 \text { a } 0,2 \\
+1 \text { a } 2\end{array}$ & $\begin{array}{c}\text { Caprinos e } \\
\text { ovinos }\end{array}$ & 45 minutos & Cetamina: $1 \mathrm{mg} / \mathrm{kg}$ \\
\hline Xilazina & $\begin{array}{l}0,03 \text { a } 0,05 \\
+3 \text { a } 5\end{array}$ & $\begin{array}{c}\text { Caprinos e } \\
\text { ovinos }\end{array}$ & 15 a 20 minutos & - \\
\hline \multirow[t]{2}{*}{ Cetamina $7,55,62,63$} & 0,1 a $0,2+2$ & Bovinos & 30 minutos & $\begin{array}{c}\text { Cetamina: } \\
0,75 \text { a } 1,25 \mathrm{mg} / \mathrm{kg}\end{array}$ \\
\hline & $0,1+7,5$ & Ovinos & 25 minutos & - \\
\hline $\begin{array}{c}\text { Xilazina } \\
+ \\
\text { Cetamina } \\
+ \\
\text { EGG }^{71}\end{array}$ & $\begin{array}{c}\text { 0,05 (Xilazina) } \\
+ \\
1 \text { a } 2 \text { (Cetamina) }\end{array}$ & $\begin{array}{l}\text { Bovinos e } \\
\text { ovinos }\end{array}$ & - & $\begin{array}{c}1 \text { a } 2 \mathrm{~mL} / \mathrm{kg} / \mathrm{h} \text { de solução: } \\
\text { Xilazina }(0,1 \mathrm{mg} / \mathrm{mL}) \\
+ \\
\text { Cetamina }(1 \text { a } 2 \mathrm{mg} / \mathrm{mL}) \\
+ \\
\text { EGG }(50 \mathrm{mg} / \mathrm{mL})\end{array}$ \\
\hline $\begin{array}{c}\text { Diazepam } \\
+ \\
\text { Cetamina }^{7,61,62}\end{array}$ & $0,1+4,5$ & Ovinos & 10 a 15 minutos & - \\
\hline $\begin{array}{c}\text { Xilazina } \\
+ \\
\text { Dextrocetamina }{ }^{63}\end{array}$ & $0,05+3$ & Caprinos & 15 a 20 minutos & - \\
\hline \multirow{2}{*}{ Tiletaminazolazepam ${ }^{6,64,66}$} & 4 & Bovinos & 60 minutos & - \\
\hline & 12 & Ovinos & 150 minutos & - \\
\hline $\begin{array}{c}\text { Butorfanol } \\
+ \\
\text { Tiletaminazolazepam } \\
\end{array}$ & $0,05+2$ a 4 & Ovinos & 25 a 50 minutos & - \\
\hline Tiopental ${ }^{71}$ & 7 a 20 & $\begin{array}{c}\text { Caprinos e } \\
\text { ovinos }\end{array}$ & 5 a 10 minutos & $\begin{array}{c}\text { Não se recomenda } \\
\text { bolusadicionais }\end{array}$ \\
\hline Propofol ${ }^{75}$ & 4 a 6 & $\begin{array}{l}\text { Bovinos, } \\
\text { caprinos e } \\
\text { ovinos }\end{array}$ & 15 minutos & - \\
\hline $\begin{array}{c}\text { Propofol } \\
+ \\
\text { Cetamina }^{76}\end{array}$ & $3+1$ & $\begin{array}{l}\text { Bovinos, } \\
\text { caprinos e } \\
\text { ovinos }\end{array}$ & - & $\begin{array}{c}\text { Propofol: } \\
0,2 \text { a } 0,3 \mathrm{mg} / \mathrm{kg} / \mathrm{min} \\
+ \\
\text { Cetamina: } \\
0,1 \text { a } 0,2 \mathrm{mg} / \mathrm{kg} / \mathrm{min}\end{array}$ \\
\hline Alfaxolona ${ }^{77}$ & 2 & Ovinos & 6 a 10 minutos & - \\
\hline $\begin{array}{c}\text { Medetomidina } \\
+ \\
\text { Alfaxolona }^{77}\end{array}$ & $0,002+2$ & Ovinos & 5 a 10 minutos & - \\
\hline
\end{tabular}



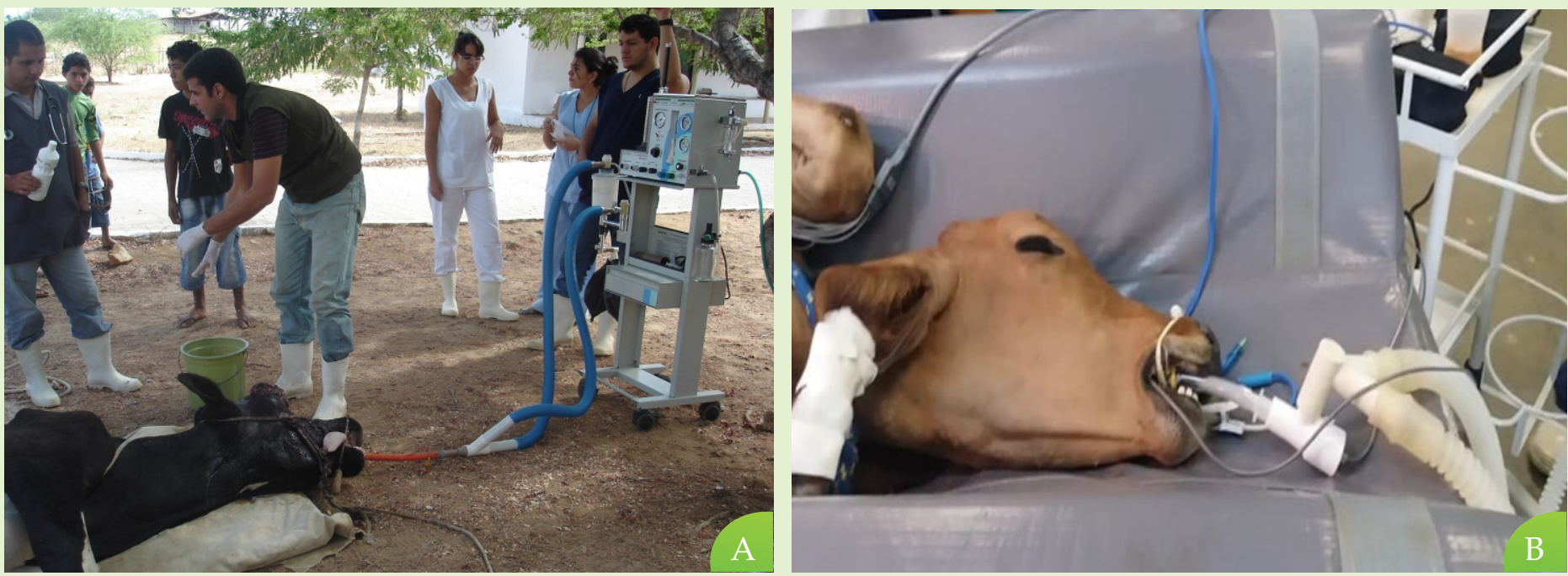

Figura 23. Anestesia inalatória em bovinos. (A) Vaca em condição a campo e (B) bezerro dentro do bloco cirúrgico (Fonte: HVU/UFCG).

mal em decúbito esternal e com auxílio do laringoscópio visualizar-se-á a laringe $e^{3,56}$. Outro aspecto relevante da intubação orotraqueal em ruminantes é que nesses animais o brônquio para o lobo cranial direito emerge diretamente da traqueia, no nível da terceira costela, o que pode facilitar a intubação seletiva desse lobo pulmonar, principalmente em pequenos ruminantes, caso se introduza a sonda orotraqueal muito caudalmente. Dessa forma, após a intubação deve-se auscultar todos os lobos pulmonares, para garantir a ventilação uniforme de todos eles ${ }^{56}$.

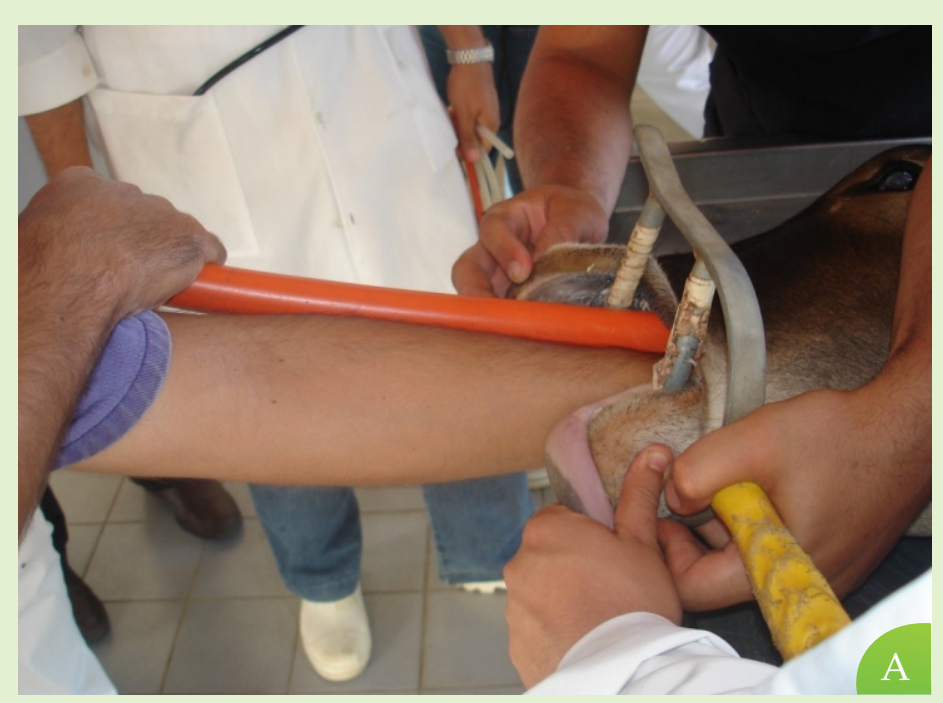

Os primeiros agentes voláteis utilizados para a manutenção da anestesia geral em ruminantes foram o halotano, o ciclopropano e o metoxifluorano ${ }^{80,81}$. Atualmente, na veterinária, os anestésicos inalatórios disponíveis e mais frequentemente usados na rotina são os halogenados: isoflurano e sevoflurano, enquanto que o desflurano ainda tem sua utilização mais restrita às pesquisas científicas ${ }^{57,82-84}$. O óxido nitroso, um gás analgésico potencializador dos agentes inalatórios, é contraindicado em ruminantes, devido ao seu potencial de se acumular em compartimentos gasosos, predis-

Figura 24. Intubação em ruminantes. (A) Palpação da laringe em bovinos e (B) visualização da laringe em caprino (Fonte: HVU/UFCG). 
pondo ao timpanismo e hipoxemia nessas espécies ${ }^{56}$.

Embora considerados seguros, os agentes inalatórios halogenados são responsáveis por reduzir de maneira dose-dependente a pressão arterial média (PAM), a frequência cardíaca e o débito cardíaco, sendo o impacto na PAM mediado primordialmente pela redução na resistência vascular sistêmica. Reduzem a taxa metabólica cerebral e o consumo de oxigênio. São capazes de inibir o reflexo do fluxo cerebral às taxas de $\mathrm{CO}_{2}$. A dilatação da vasculatura cerebral pelos anestésicos voláteis pode implicar elevação da pressão intracraniana (PIC), portanto é contraindicado em patologias que cursem com elevação da PIC como por exemplo: trauma crânio-encefálico; tumores cranianos e hidrocefalia. Em concentrações menores que 1 $\mathrm{CAM}$, em pacientes com níveis de $\mathrm{CO}_{2}$ normais, o isoflurano e o desflurano não provocam alterações na PIC. Entretanto, devido à redução da PAM, há diminuição da pressão de perfusão cerebral. Os halogenados tendem a causar depressão respiratória por redução do volume corrente e, por compensação, há elevação da frequência respiratória que não é suficiente para manter a ventilação pulmonar, elevando a $\mathrm{PaCO}_{2}{ }^{85}$.

O isoflurano é o anestésico volátil mais utilizado na prática veterinária, principalmente por apresentar menor custo em relação ao sevoflurano e ao desflurano e não requer vaporizador específico como o desflurano. Apresenta odor pungente, ponto de ebulição de $48^{\circ} \mathrm{C}$, coeficiente de solubilidade sangue-gás 1,4 e menor CAM (concentração alveolar mínima) que o sevoflurano e que o desflurano, sendo o mais potente deles $^{85}$. Assim como o sevoflurano, não sensibiliza o miocárdio às catecolaminas, por isso não tem potencial arritmogênico e apenas uma pequena fração é eliminada pelo metabolismo (0,2\%). Possibilita indução e recuperação anestésica rápidas e causa depressão cardiovascular e respiratória dose dependente, podendo se agravar em planos mais profundos ${ }^{20}$. A CAM do isoflurano em caprinos é $1,29 \%{ }^{86}, 1,27 \%$ em bovinos ${ }^{87}$ e 1,53\% em ovinos $^{88}$. Caprinos cuja indução à anestesia geral foi realizada com propofol e mantidos com uma a duas vezes a CAM do isoflurano, não apresentaram, após 15 minutos da indução, alteração na frequência cardíaca, enquanto que a pressão arterial sistêmica reduziu até o final do experimento, e mesmo em ventilação espontânea não houve impacto nos gases sanguíneos ${ }^{89}$. Em ovinos mantidos com concentração de uma a duas vezes a CAM do isoflurano apenas observou-se elevação da pressão arterial sistólica ${ }^{82}$,já em bovinos ocorreu redução da frequência cardíaca e pressão arterial, sem alterar a frequência respiratória ${ }^{84}$.

O sevoflurano é o segundo fármaco de escolha para o uso em ruminantes. É um anestésico que apresenta ponto de ebulição de $59^{\circ} \mathrm{C}, \mathrm{CAM}$ intermediária, maior que o isoflurano, mas menor que o desflurano, o que implica um agente de potência anestésica mediana, coeficiente de solubilidade sangue-gás 0,68, capaz de promover rápida indução e recuperação anestésica. Sua taxa de metabolização (5\%) é maior que a do isoflurano e do desflurano ${ }^{85}$. A CAM do sevoflurano em caprinos é 2,33\% ${ }^{86}$ e 2,7\% em ovinos ${ }^{90}$. Caprinos cuja indução à anestesia geral foi realizada com propofol e mantidos com uma a duas vezes a CAM do sevoflurano apresentaram, após 15 minutos da indução, elevação da frequência cardíaca e redução da pressão arterial sistêmica, sem alteração nos gases sanguíneos ${ }^{89}$. Em ovinos mantidos com concentração de uma a duas vezes a CAM do sevoflurano não houve mudança de padrão das frequências cardíaca e respiratória, nem da pressão arterial sistêmica $^{82}$. Já em bovinos essa mesma concentração fornecida reduziu a frequência cardíaca e a pressão arterial sistólica ${ }^{84}$ enquanto que em bezerros reduziu a pressão arterial média, elevou a $\mathrm{PaCO}_{2}$ e reduziu o $\mathrm{pH}$ do sangue arterial ${ }^{91}$.

O desflurano é um agente volátil de baixo ponto de ebulição $\left(23^{\circ} \mathrm{C}\right)$ e elevado valor de pressão de vapor, o que requer obrigatoriamente um vaporizador pressurizado e com temperatura controlada. Sua taxa de metabolização é $0,02 \%$, e seu coeficiente de solubilidade sangue-gás $(0,42)$ é o menor dentre os halogenados 
mais utilizados, o que permite a intubação dentro de dois minutos de indução com máscara ${ }^{79}$. Contudo, é um dos agentes menos potentes, com a CAM variando de $9,5 \%$ em $^{\text {ovinos }^{92} \text { a } 9,81 \% \text { em bovinos }}{ }^{83}$. Poucas informações sobre os efeitos cardiovasculares do desflurano em ruminantes encontram-se disponíveis. Em ovinos menos de 1 CAM do desflurano (7,23\%) não causa impacto nas frequências cardíaca e respiratória, nem na pressão arterial sistêmica ${ }^{82}$.

Não houve diferença significativa nas alterações cardiovasculares, e nem no tempo de recuperação anestésica, entre os protocolos com isoflurano, sevoflurano ou desflurano em ovelhas pré-medicadas com xilazina, cetamina, midazolam e buprenorfina, embora deva-se levar em consideração que os efeitos sistêmicos e a recuperação anestésica possam ter sido influenciados pelos diferentes tempos cirúrgicos e pelo efeito residual das medicações pré-anestésicas ${ }^{82}$. O isoflurano e o sevoflurano em concentrações iniciais de 3 a $5 \%$ e 5 a $7 \%$ e manutenção de 1,5 a 3\% e 2,5 a 4\%, respectivamente, em bezerros, não impactaram significativamente os sistemas cardiovascular e respiratório, implicando em efeitos semelhantes em ambos os protocolos, sem complicações em nenhum deles ${ }^{84}$. Da mesma forma, os efeitos do isoflurano e do sevoflurano foram comparados em bezerros induzidos à anestesia geral via máscara. Concluiu-se que o relaxamento muscular, a qualidade de indução e recuperação anestésica e os efeitos cardiovasculares não diferiram estatisticamente entre os agentes inalatórios, sendo ambos seguros para indução e manutenção da anestesia geral em bezerros ${ }^{93}$.

A comparação dos efeitos dos agentes voláteis isoflurano e sevoflurano foi realizada em caprinos induzidos à anestesia com o propofol. A redução na frequência cardíaca e na pressão arterial foi mais intensa com o isoflurano, quando comparado ao sevoflurano, e a recuperação anestésica foi mais rápida com o sevoflurano, mas a qualidade de indução, recuperação e efeitos adversos foram semelhantes entre os dois anestésicos ${ }^{89}$. Outros estudos não demostraram diferenças estatisticamente significativas na depressão circulatória e respiratória causadas pelo isoflurano e sevoflurano em caprinos, seja em ventilação espontânea ou contro$\operatorname{lada}^{86}$.

Por fim, observa-se que, nos artigos pesquisados, o impacto cardiovascular e respiratório é dosedependente para todas as espécies, e embora o sevoflurano tenha apresentado menores tempos de indução e recuperação anestésica, quando comparado ao isoflurano, essas diferenças não foram estatisticamente significativas, a ponto de indicar um ou outro agente sem que se priorize os custos de aquisição. 


\section{CONSIDERAÇÕES FINAIS}

As particularidades anatômicas e fisiológicas dos ruminantes, especialmente as relacionadas ao sistema digestório, tornam a anestesia nestes animais bastante peculiar. A maioria dos procedimentos cirúrgicos em ovinos, caprinos e bovinos pode ser realizado sob anestesia local, geralmente associada à sedação, empregando técnicas infiltrativas, perineurais, intravenosas ou do neuroeixo, as quais também devem ser executadas quando do emprego das anestesias intravenosa e/ou inalatória, visando bloquear a aferência dos impulsos nervosos dolorosos e evitar a sensibilização central. Quando necessária a imobilização completa do paciente, as técnicas de anestesia intravenosa ou inalatória podem ser empregadas, sempre atentando para que todas as medidas para evitar a regurgitação/aspiração de fluidos sejam seguidas antes, durante e após a anestesia, como forma a evitar transtornos respiratórios. Da mesma forma, deve-se atentar para o correto posicionamento e acolchoamento do local onde o paciente será acomodado durante o decúbito, para evitarem-se problemas relacionados à neuromiopatia pós-anestésica. Por fim, é comum a ocorrência de hipoxemia durante a anestesia intravenosa, decorrente do decúbito e da depressão respiratória causada pelos fármacos, sendo sempre recomendado o fornecimento de oxigênio durante o período transanestésico.

\section{REFERÊNCIAS}

1. LUNA, S.P.L. Dor, senciência e bem-estar em animais. Senciência e dor. Ciência Veterinária nos Trópicos, v.11, supl.1,p.17-21,2008.

\section{CARREGARO, A.B.; GEHRCKE, M.I. Conten-} ção física e medicação pré-anestésica em ruminantes. In: LUNA, S.P.L; CARREGARO, A.B. Anestesia e Analgesia em Equídeos, Ruminantes e Suínos. 1ªed. São Paulo: Medvet,2019. Cap.12,p.311-331.

3. SEDDIGHI, R.; DOHERTY, T.J. Field sedation and anesthesia of ruminants. Veterinary Clinics of North America: Food Animal Practice, v.32, n.3, p.553-570, 2016.

4. WAITE, S.J. et al. Effect of sedatives on rumen motility in sheep. Small Ruminant Research, v.196, 106284,2021.
5. ABRAHAMSEN, E.J. Chemical restraint and injectable anesthesia of ruminants. Veterinary Clinics of North America: Food Animal Practice, v.29, n.1, p.209$227,2013$.

6. RIEBOLD, T.W. Ruminantes.In: GRIMM, K.A.et al. Lumb \& Jones Anestesiologia e Analgesia Veteriná-

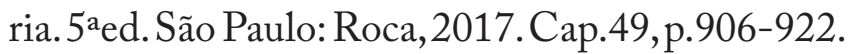

7. TAYLOR, P.M. Anesthesia in sheep and goats. In Practice.v.13,n.1,p.31-36,1991.

8. FERREIRA, D.O.L. et al. Urolitíase obstrutiva em ovinos. Veterinária e Zootecnia, v.22, n.2, p.183-197, 2015.

9. HODGSON, D.S. et al. Effects of acepromazine and xylazine on uterine blood flow and oxygen delivery in pregnant cows. American Journal of Veterinary Research,v.63,n.12,p.1695-1699, 2002. 
10. RAEKALLIO, M. et al. Medetomidinemidazolam sedation in sheep. Acta Veterinaria Scandinavica, v.39, n.1,p.127-134,1998.

11. DZIKITI, T.B. Intravenous anaesthesia in goats: a review. Journal of the South African Veterinary Association, v.84, n.1,E1-8,2013.

12. LIN, H. Standing sedation and chemical restraint. In: LIN, H.; WALZ, P. Farm Animal Anesthesia: Cattle, Small Ruminants, Camelids, and Pigs. $1^{\text {aed. New }}$ Jersey:John Wiley \& Sons, 2014. Cap.3,p.39-59.

13. RIZK, A. et al. Effects of xylazine hydrochloride on hormonal, metabolic, and cardiorespiratory stress responses to lateral recumbency and claw trimming in dairy cows. Journal of the American Veterinary Medical Association,v.240, n.10, p.1223-1230,2012.

14. CELLY, C.S. et al. Histopathologic alterations induced in the lungs of sheep by use of alpha2adrenergic receptor agonists. American Journal of Veterinary Research,v.60,n.2,p.154-161,1999.

15. SAKAMOTO, H. et al. The effects of xylazine on intrauterine pressure, uterine blood flow, maternal and fetal cardiovascular and pulmonary function in pregmant goats. Journal of Veterinary Medical Science, v.58, n.3, p.211-217, 1996.

16. BROCKMAN, R.P. Effect of xylazine on plasma glucose, glucagon and insulin concentrations in sheep. Research in Veterinary Science, v.30, n.3, p.383-384, 1981.

17. RIBEIRO, G. et al. Efeitos de detomidina e xilazina intravenosa sobre as variáveis basais e respostas comportamentais em bovinos. Arquivos Brasileiro de Medicina Veterinária e Zootecnia, v.64, n.6, p.1411$1417,2012$.
18. KHAN, M.A. et al. Comparative effects of detomidine and xylazine as sedative and analgesic agents in small ruminants. Pakistan Veterinary Journal, v.24, n.2,p.62-69, 2004.

19. LIN, H.C.; PUGH, D.G. Procedimentos anestésicos. In: PUGH, D.G. Clínica de Ovinos e Caprinos. São Paulo: Roca,2005.Cap.14,p.455-470.

20. GALATOS, A.D. Anesthesia and analgesia in sheep and goats. Veterinary Clinics of North America: Food Animal Practice, v.27, n.1,p.47-59,2011.

21. MOOLCHAND, M. et al. Comparison of effects of xylazine, detomidine and medetomidine on heart rate, respiratory rate and blood glucose level in sheep. Pakistan Journal of Agriculture, Agricultural Engineering andVeterinary Sciences, v.31, n.1,p.93-101,2015.

22. PESHIN, P.K. et al. Sedative effect of detomidine in infant calves. Acta Veterinarica Hungarica, v.39, n.3-4, p.103-107,1991.

23. MOURA, R.S. et al. Sedative and cardiorespiratory effects of detomidine constant rate infusion in sheep. Laboratory Animals, v.52, n.1, p.51-58,2018.

24. RANKIN, D.C. Sedativos e tranquilizantes. In: GRIMM, K.A. et al. Lumb \& Jones Anestesiologia e Analgesia Veterinária. 5aed. São Paulo: Roca, 2017. Cap.10,p.188-198.

25. CAGNARDI, P. et al. Pharmacokinetics and sedative effects of dexmedetomidine in dairy calves. New Zealand Veterinary Journal,v.65,n.1, p.14-18,2017.

26. BORGES, L.P.B. et al. Behavioral and cardiopulmonary effects of dexmedetomidine alone and in combination with butorphanol, methadone, morphine or tramadol in conscious sheep. Veterinary 
Anaesthesia and Analgesia, v.43, n.5, p.549-560, 2016.

27. PONTAROLO, D.V. et al. Estudo comparativo dos efeitos da dexmedetomidina e xilazina em bovinos submetidos a lavado broncoscópico.In:ZUFFO, A.M. A Produção do Conhecimento nas Ciências Agrárias e Ambientais. Ponta Grossa: Atena, 2019. v.3, Cap.12, p.127-135.

28. UEMURA, K. et al. Maternal and preterm fetal sheep responses to dexmedetomidine. International Journal of Obstetric Anesthesia, v.21, n.4, p.339-347, 2012.

29. RAEKALLIO, M.R. et al. The effects of L659,066 , a peripheral $\alpha_{2}$-adrenoceptor antagonist, and verapamil on the cardiovascular influences of dexmedetomidine in conscious sheep. Journal of Veterinary Pharmacology and Therapeutics, v.33, n.4, p.434438,2010 .

30. KÄSTNER, S.B.R. et al. Dexmedetomidineinduced pulmonary alterations in sheep. Research in Veterinary Science, v.83, n.2,p.217-226, 2007.

\section{ANDERSON, D.E.; EDMONDSON, M.A.} Prevention and management of surgical pain in cattle. Veterinary Clinics of North America: Food Animal Practice,v.29, n.1, p.157-184,2013.

32. OUTEDA, N.C.; CARREGARO, A.B. Farmacocinética aplicada à anestesiologia. In: LUNA, S.P.L; CARREGARO, A.B.Anestesia e Analgesia em Equídeos, Ruminantes e Suínos. São Paulo: Medvet, 2019. Cap.2,p.15-31.

33. MORAES, A.N. et al. Administração epidural de ropivacaína isolada ou associada à xilazina em bovinos. Semina: Ciências Agrárias, v.35, n.4, p.2481-2490, 2014.
34. DEROSSI, R. et al. The efficacy and safety of levobupivacaine administered by lumbosacral epidural route in conscious sheep. Research in Veterinary Science, v.92,n.2,p.278-282, 2012.

35. CHANG, D.H.T. et al. Tolerability of large-dose intravenous levobupivacaine in sheep. Anesthesia $\mathcal{E}^{\circ}$ Analgesia.v.91,n.3, p.671-679, 2000.

36. SEN, O. et al. Avaliação da lesão do nervo ciático após injeção intraneural de bupivacaína, levobupivacaína e lidocaína em ratos. Revista Brasileira de Anestesiologia.v.66,n.3,p.272-275,2016.

37. COPELAND, S.E. et al. The effects of general anesthesia on the central nervous and cardiovascular system toxicity of local anesthetics. Anesthesia $\Xi^{\circ}$ Analgesia.v.106, n.5, p.1429-1439,2008.

38. MORISHIMA, H.O. et al. Toxicity of lidocaine in adult, newborn, and fetal sheep. Anesthesiology. v.55, n.1,p.57-61.1981.

39. HABEL, R.; BUDRAS, K.D. Central nervous system and cranial nerves. In: BUDRAS, K.D.; HABEL, R. Bovine Anatomy. 2aed. Hannover, Schlutersche, 2011.p.30-49.

40. VALVERDE, A.; SINCLAIR, M. Técnicas de anestesia local e analgésicas em suínos e ruminantes. In: GRIMM, K.A. et al. Lumb \& Jones Anestesiologia e Analgesia Veterinária. 5aed. São Paulo: Roca, 2017. Cap.51,p.937-955.

41. VALVERDE, A., DOHERTY, T.J. Anesthesia and analgesia in ruminants. In: FISH, R. Anesthesia and Analgesia in Laboratory Animals. 2aed. San Diego: Academic Press,2008.p.385-412.

42. QUEVEDO, D.A.C. et al. Tratamiento quirúrgico 
en las etapas de desarrollo del carcinoma ocular de células escamosas en bovinos del trópico alto del departamento de Nariño. CES Medicina Veterinaria y Zootecnia,v.14, n.3,p.98-109, 2019.

43. SANTOS, P.S.P. et al. Anestesia locorregiomal em ruminantes e suínos. In: LUNA, S.P.L; CARREGARO,A.B.Anestesia e Analgesia em Equídeos, Ruminantes e Suínos. São Paulo: Medvet, 2019. Cap.14,p.397-436.

44. SKARDA, R.T.; TRANQUILLI, W.J. Local anesthetics. In: TRANQUILLI, W.J. et al. Lumb \& Jones' Veterinary Anesthesia and Analgesia. 4aed. Oxford:Blackwell,2007. Cap.14,p.395-418.

45. FEITOSA, F.L.F. Semiologia Veterinária - A Arte do Diagnóstico. 4.ed. Rio de Janeiro: Guanabara Koogan.2020.p.670.

46. JOHNSON, R.A. et al. Cephalad distribution of three different volumes of new methylene blue injected into the epidural space in adult goats. Veterinary Surgery, v.25, n.5, p.448-451, 1996.

47. BUDRAS, K.D.; HABEL, R. Special anatomy, tabular part. In: BUDRAS, K.D.; HABEL, R. Bovine Anatomy. 2aed. Hannover: Schlutersche, 2011.p.119125.

48. MUHAMMAD, Y.J. et al. Xylazine and lidocaine: uses of high epidural anesthesia in the domesticated small animals. Punjab University Journal of Zoology, v.36, n.1,p.31-36,2021.

49. SILVA, L.S. et al. Administração epidural caudal de xilazina ou tramadol em vacas. Brazilian Journal of Animal and Environmental Research, v.2, n.1, p.482489,2019.
50. RODRIGUES, S.D. et al. Avaliação da anestesia epidural com dexmedetomidina ou xilazina associada a lidocaína em ovinos evaluation of epidural anesthesia with lidocaine and dexmedetomidine or lidocaine and xylazine in sheep. In: CONGRESSO BRASILEIRO DE ANESTESIOLOGIA VETERINÁRIA, 13, 2018,Brasília.Anais ... Brasília,p.36,2018.

51. GHADIRIAN, S. et al. Comparison of lidocaine, lidocaine-morphine, lidocaine-tramadol or bupivacaine for neural blockade of the brachial plexus in fat-tailed lambs. Veterinary Anaesthesia and Analgesia,v.43,n.1,p.109-116,2016.

52. EDMONDSON, M.A. Local, regional and spinal anesthesia in ruminants. Veterinary Clinics of North America: Food Animal Practice, v.32, n.5, p.535-552, 2016.

53. COETZEE, J.F.et al. An update on the assessment and management of pain associated with lameness in cattle. Veterinary Clinics of North America: Food Animal Practice.v.33, n.2, p.389-411,2017.

54. YAVARI, S. et al. Evaluation of intravenous regional anaesthesia and four-point nerve block efficacy in the distal hind limb of dairy cows. BMC Veterinary Research,v.13,n.1,p.320,2017.

55. BERRY, S. H. Anestésicos injetáveis. In: GRIMM, K.A. et al. Lumb \& Jones Anestesiologia e Analgesia Veterinária. 5aed. São Paulo: Roca, 2017. Cap.14, p.271-290.

56. CARROLL, G. L.; HARTSFIELD, S. M. General anesthetic techniques in ruminants. Veterinary Clinics of North America: Food Animal Practice, v.12, n.3, p.627-661, 1996.

57. YAYGINGUL, R. et al. Comparison of clinical and 
hemodynamic effects of isoflurane and sevoflurane anesthesia in calves. Acta Scientiae Veterinariae, v.45, n.1,Pub.1497, 2017.

58. HALL, L.W.; CLARKE, K.W.Veterinary Anaesthesia. 9aed. London: Baillière Tindall, 1991. p.236259.

59. RANG, H.P. et al. Agentes anestésicos gerais. In: RANG, H.P. et al. Hang \& Dale: Farmacologia. $8^{a}$ ed. Rio de Janeiro: Elsevier,2016. Cap.41,p.1167-1190.

60. VLERICK, L. et al. Pharmacokinetics, absolute bioavailability and tolerability of ketamine after intranasal administration to dexmedetomidine sedated dogs. PloS One,v.15, n.1,p.1-13,2020.

61. TAKESHITA, H. et al. The effects of ketamine on cerebral circulation and metabolism in man. Anesthesiology,v.36, n.1, p.69-75, 1972.

62. THURMON, J.C.; BENSON, G.J. Anesthesia in ruminants and swine. In: HOWARD, J.C. Current Veterinary Therapy 3: Food Animal Practice. 3aed. Philadelphia:WB Saunders, 1993.p.58-76.

63. COULSON, N.M. et al. The cardiorespiratory effects of diazepam-ketamine and xylazine-ketamine anesthetic combinations in sheep. Laboratory Animal Science, v.39, n.6,p.591-597,1989.

64. GRAY, P.R. Anesthesia in goats and sheep. Part II. General anesthesia. Compendium on Continuing Education for the Practising Veterinarian, v.8, p.127-135, 1986.

65. ALBUQUERQUE, E.E. Efeitos da cetamina e da dextrocetamina em caprinos da raça Moxotó. 2017. 74f. Dissertação (Mestrado) - Programa de Pósgraduação em Medicina Veterinária, Universidade
Federal de Campina Grande, Patos, Paraíba.

66. LIN, H.C. et al. Hemodynamic response of calves to tiletamine-zolazepam-xylazine anesthesia. American Journal of Veterinary Research, v.52, n.10, p.1606$1610,1991$.

67. ABRAHAMSEN, E.J. Ruminant field anesthesia. Veterinary Clinics of North America: Food Animal Practice, v.24, n.3, p.429-441,2008.

68. CONNER, G.H. et al. Laboratory use of CI-744, a cataleptoid anesthetic, in sheep. Veterinary Medicine Small Animal Clinician, v.69, n.4,p.479-482,1974.

69. HOWARD, B.W. et al. The cardiovascular response of sheep to tiletamine-zolazepam and butorphanol tartrate anesthesia. Veterinary Surgery, v.19, n.6, p.461-467,1990.

70. SANTOS, P.S.P. et al. Anestesia total intravenosa (ATI) para herniorrafias umbilicais em bezerros. Veterinária e Zootecnia,v.17, n.1,p.54-61,2010.

71. PANG, D.S.J. Anestésicos e analgésicos adjuvantes. In: GRIMM, K.A. et al. Lumb \& Jones Anestesiologia e Analgesia Veterinária. 5aed. São Paulo: Roca, 2017. Cap.13,p.724-297.

72. PICAVET, M.T.J.E. et al. Cardiopulmonary effects of combined xylazine-guaiphenesin-ketamine infusion and extradural (inter-coccygeal lidocaine) anaesthesia in calves. Veterinary Anaesthesia and Analgesia, v.31, n.1,p.11-19,2004.

73. HALL, L.W. et al. Anaesthesia of sheep, goats and outher herbivores. In: HALL, L. et al. Veterinary Anaesthesia. 10aed. London: WB Saunders, 2001. p.34166. 
74. MASSONE, F.; CORTOPASSI, S.R.G. Anestesia intravenosa. In: FANTONI, D.T.; CORTOPASSI, S.R.G. Anestesia em Cães e Gatos. 2aed. São Paulo: Roca, 2009. Cap.14,p.228-236.

75. DUKE, T. et al. Cardiopulmonary effects of propofol infusion in llamas. American Journal of Veterinary Research, v.58, n.2,p.153-156, 1997.

76. CORREIA, D. et al. Pharmacokinetics of propofol infusions, either alone or with ketamine, in sheep premedicated with acepromazine and papaveretum. Research in Veterinary Science, v.60, n.3, p.213-217, 1996.

77. WALSH, V.P. et al. A comparison of two different ketamine and diazepam combinations with an alphaxalone and medetomidine combination for induction of anaesthesia in sheep. Nerw Zealand Veterinary Journal, v.60, n.2, p.136-141,2012.

78. LIN, H. Inhalation anesthesia. In: LIN, H.; WALZ, P. Farm Animal Anesthesia: Cattle, Small Ruminants, Camelids, and Pigs. 1aed. New Jersey: John Wiley \& Sons, 2014. Cap.5, p.95-110.

79. MALIK, V. An update on general anaesthesia in ruminants. Indian Journal of Veterinary Surgery, v.35, n.1,p.1-11,2014.

80.TAVERNOR,W.D. Anaesthetic procedures in the larger domesticated animals. Journal of the Royal Society of Medicine, v.53, n.9, p.717-720,1960.

81. HORNEY, F.D. Anesthesia in the bovine. The Canadian Veterinary Journal, v.7, n.10, p.224-232, 1966.

82. MOHAMADNIA, A. et al. Maintenance of anaesthesia in sheep with isoflurane, desflurane or sevoflurane. Veterinary Record, v.163, n.7, p.210-215, 2008.

83. COLUMBANO, N. et al. Determination of the minimum alveolar concentration (MAC) and cardiopulmonary effects of sevoflurane in sheep. Veterinary Anaesthesia and Analgesia, v.45, n.4, p.487495,2018.

84. YAKAN, S.; AKSOY, O. Comparison of the effects of isoflurane and sevoflurane general anaesthesia after induction by propofol on clinical and physiological measurements in calves. Acta Scientiae Veterinariae, v.47,n.1,p.1659-1668, 2019.

85. KHAN, K.S. et al. Pharmacology of anaesthetic agents II: inhalation anaesthetic agents. Continuing Education in Anaesthesia Critical Care E Pain, v.14, n.3, p.106-111,2014.

86. HIKASA, Y. et al. Anesthetic potency and cardiopulmonary effects of sevoflurane in goats: Comparison with isoflurane and halothane. Canadian Journal of Veterinary Research, v.62, n.4, p.299-306, 1998.

87. CANTALAPIEDRA, A.G. et al. Anaesthetic potency of isoflurane in cattle: determination of the minimum alveolar concentration. Veterinary Anaesthesia and Analgesia, v.27,n.1,p.22-26,2000.

88. BERNARDS, C.M. et al. Chronic cocaine administration reversibly increases isoflurane minimum alveolar concentration in sheep. Anesthesiology, v.85, n.1,p.91-95, 1996.

89. KUMANDAŞ, A.; ELMA, E. Comparison of sevoflurane and isoflurane effects on cardiovascular and respiratory system during spontaneous ventilation in Angora goats. Turkish Journal of Veterinary and Ani- 
mal Sciences, v.39, n.4,p.501-506,2015.

90. COLUMBANO, N. et al. Determination of minimum alveolar concentration and cardiovascular effects of desflurane in positive-pressure ventilated sheep. American Journal of Veterinary Research, v.79, n.7, p.727-732,2018.

91. GREENE, S.A. et al. Cardiovascular effects of sevoflurane in Holstein calves. Veterinary Anaesthesia and Analgesia, v.29, n.2, p.59-63, 2002.

92. LUKASIK, C. et al. (1998) citado por MOHAMADNIA, A. et al. Maintenance of anaesthesia in sheep with isoflurane, desflurane or sevoflurane. Veterinary Record, v.163, n.7, p.210-215, 2008.

93. YAKAN, S. et al. Comparison of use of isoflurane or sevoflurane for anaesthesia induced by mask in calves. Acta Scientiae Veterinariae, v.48, Pub.1776, 2020. 